Anti Selart, Andres Tvauri, Alar Läänelaid

\title{
DIE BURG WARBECK (KASTRE)
}

Die Burg Warbeck (estnisch Kastre, manchmal auch als Uue- (Neu-) Kastre bezeichnet) am Nordufer des Embachs (Emajõgi) ist bis heute praktisch komplett zerstört. Sie gehörte einst den Bischöfen von Dorpat (Tartu), an der Burg verlief ein Handelsweg, der über Dorpat und Pleskau (Pskov) die Ostseeanrainer und Russland verband. Die Archive des Bistums und der mittelalterlichen Stadt Dorpat sind leider vernichtet und über die ältere Geschichte der Burg bieten nur zufällige Briefe Informationen, in denen aus irgendeinem Grund Warbeck erwähnt wurde und die beispielsweise über Reval (Tallinn) oder Lübeck auf uns gekommen sind. Aus der Sicht der heutigen Transportwege befindet sich die Burg an einem abgelegenen Ort. Hier endet der von Westen kommende, sichere und befestigte Weg, denn weiter bis zum Peipussee (Peipsi järv) erstrecken sich die nahezu unbewohnten Gebiete des Großen Moores (Suursoo) des

DOI: https://doi.org/10.12697/BJAH.2017.13.03

Übersetzung aus dem Estnischen von Marju und Olaf Mertelsmann.

Das Erscheinen dieses Beitrags wurde gefördert durch das institutionelle Forschungsförderungsprojekt IUT20-7 „Estland im Ostseeraum: Archäologie von wirtschaftlichen, sozialen und kulturellen Prozessen" sowie das persönliche Forschungsförderungsprojekt PUT 1422 „Gemeinsames Leben, Abgetrenntheit und kulturelle Interaktion im mittelalterlichen Livland (1200-1550)“.

Abkürzungen: AI - Archäologische Sammlung der Universität Tallinn (Tallinna Ülikooli arheoloogia teaduskogu); ERM A - Sammlung von Gegenständen des Estnischen Nationalmuseums (Eesti Rahva Muuseumi esemekogu); TÜ - Archäologische Sammlung der Abteilung für Archäologie der Universität Tartu (Tartu Ülikooli arheoloogia osakonna arheoloogiakogu). 
Embachs. So erscheint es als kein Wunder, dass obwohl gesondert genommen nicht so wenig Beschreibungen Warbecks erschienen sind, ${ }^{1}$ es sich doch um eine der wenig bekannten Burgen Estlands handelt.

Dennoch verdient die Burg Warbeck mehr Aufmerksamkeit, dies in erster Linie wegen ihrer geografischen Lage: hier verlief die wirkliche Ostgrenze des Bistums Dorpat. Die Burg Warbeck wurde in schriftlichen Quellen erstmals im Jahr 1392 erwähnt, nämlich als Zollstelle an der Grenze. Damals wurde nach einer langen Periode des Konflikts zwischen den Hansestädten und Nowgorod (Novgorod) ein Vertrag abgeschlossen, bekannt als "Nieburfrieden“. So wurde er nämlich benannt nach dem Lübecker Ratsherren Johann Niebur, der an den erwähnten Verhandlungen teilnahm. Im Text des Vertrags wird ein „Baum“ oder ein „Balken“ (колода, ьоет balke) erwähnt, der sich auf dem Embach bei der Burg Warbeck des Dorpater Bischofs befand und wo die Nowgoroder Kaufleute das Recht auf "freien Weg“ erhalten sollten, also die Befreiung vom Zoll und von anderen Abgaben. ${ }^{2}$ Der „Nieburfrieden“ legte die Grundlage für die Beziehung der Kaufmannschaft Nowgorods und der Hanse für das gesamte folgende Jahrhundert. Klar ist, dass als Warbecks „Baum“ bei den dem Vertrag vorhergehenden Verhandlungen in Izborsk 1391 behandelt wurde, dann müsste das Problem - die Erhebung von Abgaben in der Mündung des Embach durch den

1 Eduard Philipp Körber, „Einige Notizen über das Schloß Warbeck“, Das Inland, Nr. 10, 04.03.1836, Spalte 159-160; Karl von Löwis of Menar, „Die Ruine der Deutschordensvogtei Neuschloß an der Narowa bei Sirenetz", Revalsche Zeitung, Nr. 265, 18.11.(01.12.)1910; Nr. 266, Walters und Rapa, 1922), 120-121; Otto Freymuth, „Kastre lahing“, Odamees, 17 (1924), 67-68, hier 68; Armin Neumann [Tuulse], Eesti lossid. Kronoloogia ja plaanitüübid. Magisterarbei (Tartu, 1934), 82-84. Handschrift in der Universitätsbibliothek Tartu; Armin Tuulse, Die Burgen in Estland und Lettland (Dorpat: Dorpater Estnischer Verlag, 1942), 97-98; [Augus Traat], Ajalooline Emajõgi (Tallinn: Eesti Raamat, 1968), 52-57; Uno Hermann, „,Keskaegsed asulad Emajõe alamjooksul“", Eesti Loodus, 3 (1974), 156-159; Kalvi Aluve, Eesti keskaegsed linnused (Tallinn: Valgus, 1993), 59; Kristin Marmei, 300 aastat kuulsast Emajõe jõelahingus Tartu: Marmei, 2004), 4; Ants Hein, „Kastre/Warbeck“", Johann Christoph Brotze, Estonica, hrsg. von Ants Hein, Ivar Leimus, Raimo Pullat, Ants Viires (Tallinn: Estopol, 2006), 403-405.

2 Liv-, Esth- und Curländisches Urkundenbuch nebst Regesten, Bd. 3, hrsg. von Friedrich Geors von Bunge (Reval: Kluge und Ströhm, 1857), Nr. 1330/2, 698; Nr. 1330/3, 698; Die Recesse und andere Akten der Hansetage von 1256-1430, Bd. 4, hrsg. von Karl Koppmann (Leipzig: Duncke \& Humblot, 1877), Nr. 45, 50. Übereinkunft in allen Redaktionen, der Name der Burg wird nich erwähnt. Vgl. Liv-, Esth- und Curlandisches Urkundenbuch nebst Regesten, Bd. 6, hrsg. von Friedrich Georg von Bunge (Riga: N. Kymmel, 1873), Nr. 2924; Leopold Karl Goetz, DeutschRussische Handelsverträge des Mittelalters. Abhandlungen des Hamburgischen Kolonialinstituts, Bd. 37. Serie A. Rechts- und Staatswissenshiafin, Bd. 6 (Hamburg. Firederichsen \& Co., 1916), 190; Natal'ja A. Kazakova, Russko-livonskie i russko-ganzejskie otnošenija. Konec XIV-nača XVI v. (Leningrad: Nauka, 1975), 82.
Dorpater Bischof - bereits vorher entstanden sein und auch die Burg musste schon früher bestanden haben. Nach Informationen des deutschbaltischen Historikers des 18. Jahrhunderts, Johann Gottfried Arndt (1713-1767), errichtete der Dorpater Bischof Friedrich die Burg Warbeck im Jahr $1279,{ }^{3}$ doch wir wissen nicht, wo Arndt seine Angaben über die Bauzeit livländischer Burgen gefunden hatte und sie fanden bisher auch keine Anerkennung. Der fantasiereiche Hobbyhistoriker Edgar Valter Saks (1910-1984) sah 1979 den Beginn der Burg in einer vorzeitlichen estnischen Verteidigungsanlage ,kasti', doch er fügte einschränkend hinzu: „Das letzte Wort haben hier die Archäologen". ${ }^{4}$

$\mathrm{Zu}$ diesem Zeitpunkt hatten Forschungsarbeiten vor Ort tatsächlich bereits begonnen. Als erste in der Burg erfolgte Untersuchung kann die des Geodäten Uno Hermann (1922-2005) zum Grundriss der Burg angesehen werden, die im Jahre 1973 erfolgte. Zusätzlich zum Grundriss erstellte er auch eine Übersicht über die Geschichte der Burg. ${ }^{5}$ Auf dem Grundriss vermerkte er ebenso die damals noch zu erkennenden Mauerreste, die am Flussufer freigelegten Reste der Balkenunterlagen sowie die Wallgräben der Burg und der Vorburg. Unter anderem die Tatsache verleiht dem Plan Uno Hermanns einen zusätzlichen Wert, dass auf ihm die ursprüngliche Lage der Wallgräben dokumentiert ist, die bis heute nicht mehr erhalten geblieben ist. Nämlich ließ der damalige Besitzer des Areals der Burg im Jahre 1993 die diese und die Vorburg umgebenden Wallgräben vertiefen und erweitern, als dessen Ergebnis deren Standort und Erscheinungsbild sich erheblich veränderte. Die Feststellung des erzeugten Schadens dieser eigenmächtigen Grabungsarbeiten ist verbunden mit den ersten archäologischen Untersuchungen in der Burg. 1994 dokumentierten Riina Vesi und Erik Tootsi die als Ergebnis des Wühlens des Baggers in den Wallgräben entblößten Erdbodenprofile. ${ }^{6}$ Aus dem aus den Wallgräben ausgehobenem

3 Johann Gottfried Arndt, Der Liefländischen Chronik Andrer Theil (Halle: Gebauer, 1753), 347 4 Edgar Valter Saks, ,Juba ,vene viikingid!““”, Tulimuld, 3 (1979), 167; vgl. Felix Oinas, ,Veel kord Kastre nimest“", Tulimuld, 1 (1980), 54

5 Uno Hermann, Ajalooline õiend Uue-Kastre piiskopilinnuse kohta (Tallinn, 1973). Das Manuskript befindet sich im Archiv des Amtes für Denkmalschutz, Tallinn

6 Riina Vesi, Erik Tootsi, Aruanne arheoloogilistest uurimistöödest Uue-Kastre linnusel 24.-26. augustil ja 7. septembril 1994. a. (Tartu, 1994). Handschrift im Archiv des Amtes fü Denkmalschutz, Tallinn. 


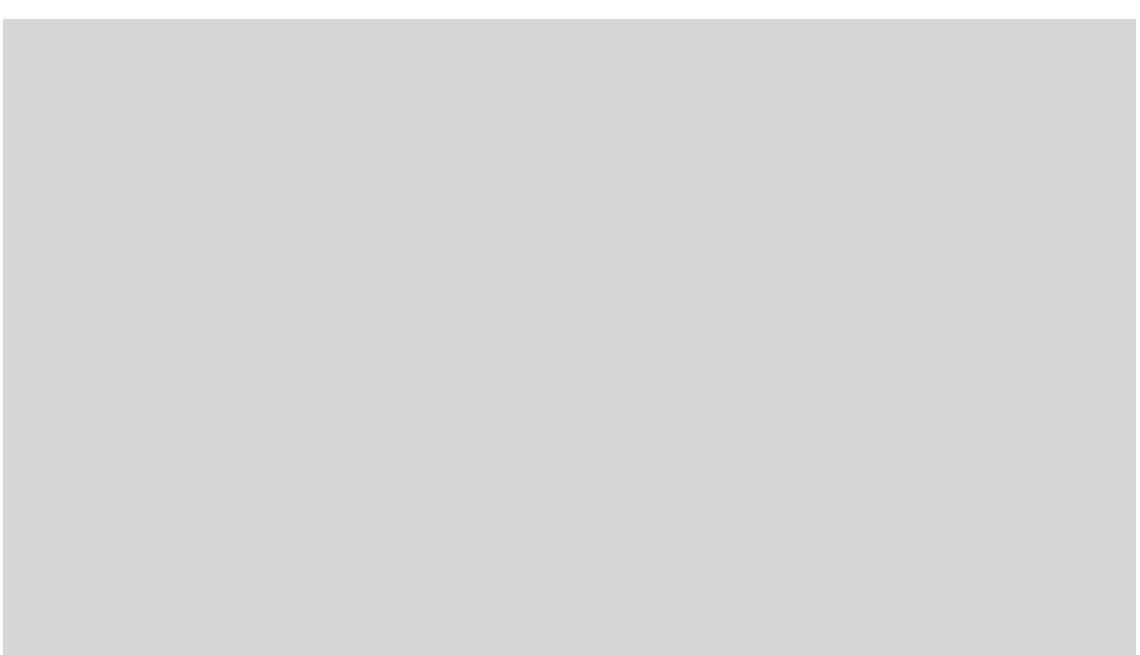

Abb. 1. Ansicht des Krugs am Ort der Burg Warbeck vom Westen aus im Jahr 1800. Eduard Philipp Körber, Vaterländische Merkwürdigkeiten I (1802), 312. Estnisches Kulturhistorische Archiv des Estnischen Literaturmuseums, Tartu.

Schlamm sammelte man auch einige Funde, ${ }^{7}$ die aber auch aus einer Zeit nach der Burg stammen könnten.

Im Jahr 2001 erfolgten unter Leitung von Andres Tvauri die ersten archäologischen Ausgrabungen in der früheren Burg Warbeck. ${ }^{8}$ Zwischen den Mauern des am Standort der Burg am Ende des 18. und zu Beginn des 19. Jahrhunderts erbauten Krugs (Kantsi ${ }^{9}$ kõrts, Abb. 1) wurde ein Neubau geplant und die dafür nötigen Vertiefungen wurden im Rahmen einer archäologischen Rettungsgrabung ausgehoben. Die Aufsicht über die Bauarbeiten sowie die Säuberungen der Wallgräben und die mit der Gestaltung der Umgebung verbundenen Grabungsarbeiten setzte sich auch in den nächsten zwei Jahren fort. ${ }^{10}$

7 TÜ 175.

8 Andres Tvauri, Aruanne arheoloogilistest kaevamistest Uue-Kastre piiskopilinnusel 2001. aastal (Tartu, 2001). Handschrift im Archiv des Amtes für Denkmalschutz, Tallinn.

9 Kants - auf Estnisch ,Burg` oder ,Festung ${ }^{6}$.

10 Andres Tvauri, „Archaeological investigations at the Bishops's Castle of Varbek (Kastre)“, Archaeological Fieldwork in Estonia / Arheoloogilised välitööd Eestis 2001 (Tallinn Muinsuskaitseamet, 2002), 152-159; Andres Tvauri, Aruanne arheoloogilistest uuringutest UueKastre piiskopilinnusel 2001. aasta sügisel ning 2002. ja 2003. aastal (Tartu, 2004). Handschrift im Archiv des Amtes für Denkmalschutz, Tallinn.
Bei den Ausgrabungen wurde am vermuteten Standort des Hofs und der Innenräume der Burg das Kopfsteinpflaster in der Tiefe von 40-120 cm von der Erdoberfläche, die vor den Grabungsarbeiten vorlag, erreicht (Abb. 2). Zur Errichtung der Fundamente des Neubaus war es nicht nötig, tiefer zu graben, und es wurde entschieden, auch das Pflaster zu erhalten, deshalb wurden die unter dem Pflaster liegenden Schichten nur an einigen Stellen untersucht.

Ein halbes Jahrhundert vor dem Abschluss vom "Nieburfrieden“, im frühen Frühjahr 1342, führten die Pleskauer (Pskover) auf Flussschiffen kommend einen Raubzug im Bistum Dorpat bis nach der Burg Oldenthorn (Vana-Kastre) durch. ${ }^{11}$ Nach Information der Pleskauer Chroniken reichte dieser Raubzug bis zu einer kleinen Burg (городок, gorodok) namens Могилев (Mogilev). ${ }^{12}$ Der letztere Ortsname ist verbunden worden mit Falkenau (Kärkna) ${ }_{1}^{13}$ Dorpat, ${ }^{14}$ dem vorhistorischen Namen eines Landkreises, Mocha (Mõhu), ${ }^{1}$ Mäxhof (Mäksa) ${ }^{16}$ und am wahrscheinlichsten Oldenthorn. ${ }^{17}$ An dieser Stelle lässt sich die Folgerung treffen, dass die Burg Warbeck, die den Einfall der Feinde bereits an der Mündung des Embachs hätte stoppen können, damals noch nicht existierte. Laut dem deutschbaltischen Historiker Carl von Stern (1859-1944) wurde die Burg Warbeck darum recht bald nach dem Jahr 1342 errichtet, ${ }^{18}$ gemäß der Vermutung des

11 Bartholomäus Hoeneke, Liivimaa noorem riimkroonika (1315-1348), hrsg. von Sulev Vahtre (Tallinn: Eesti Riiklik Kirjastus, 1960), 72.

12 Pskovskie letopisi, Bd. 2, hrsg. von Arsenij N. Nasonov (Moskau: Izdatel'stvo Akademi nauk SSSR, 1955), 93

13 Bartholomäus Hoeneke, Liivimaa noorem riimkroonika (1315-1348), 143.

14 Ernst Bonnell, Russisch-liwländische Chronographie von der Mitte des neunten Jahrhunderts bis zum Jahre 1410 (St. Petersburg: Kaiserliche Akademie der Wissenschaften, 1862), Commentar S. 178 .

15 Ada Ambus, „Lõuna-Eesti kohanimed Pihkva kroonikais“, Keel ja Kirjandus, 12 (1960), 736-743, hier 740 .

16 Fedor A. Savichin, Aarne Kasikov, „Novyj vzgljad na formirovanie russkogo staroobrjadčestva v Zapadnom Pričud’e Esstonii (po istoričeskim i jazykovym dannym)“, Russian Linguistics, 29 (2005), 137-187, hier 145.

17 Friedrich von Keussler, „Ueber früher gebräuchliche russische Benennungen baltischer Oertlichkeiten", Sitzungsberichte der Gesellschaft für Geschichte und Alterthumskunde 24-28, 36-37, hier 28; Carl von Stern, Die bischöfliche Embachfestung Oldenthorn un, ihre verschiedenen Namen", Quellen und Forschungen zur baltischen Geschichte, 2 (1942), 43-49; [Traat], Ajalooline Emajõgi, 48-49; Jaak Simm, ,Lisa Pihkva kroonikate Lõuna-Eesti kohanimedele", Keel ja Kirjandus, 4 (1973), 223-225.

18 Carl von Stern, „Dorpat-Pleskauer Kämpfe um die Peipusfischerei 1224-1371“, Quellen und Forschungen zur baltischen Geschichte, 5 (1944), 73-123, hier 114-115. 


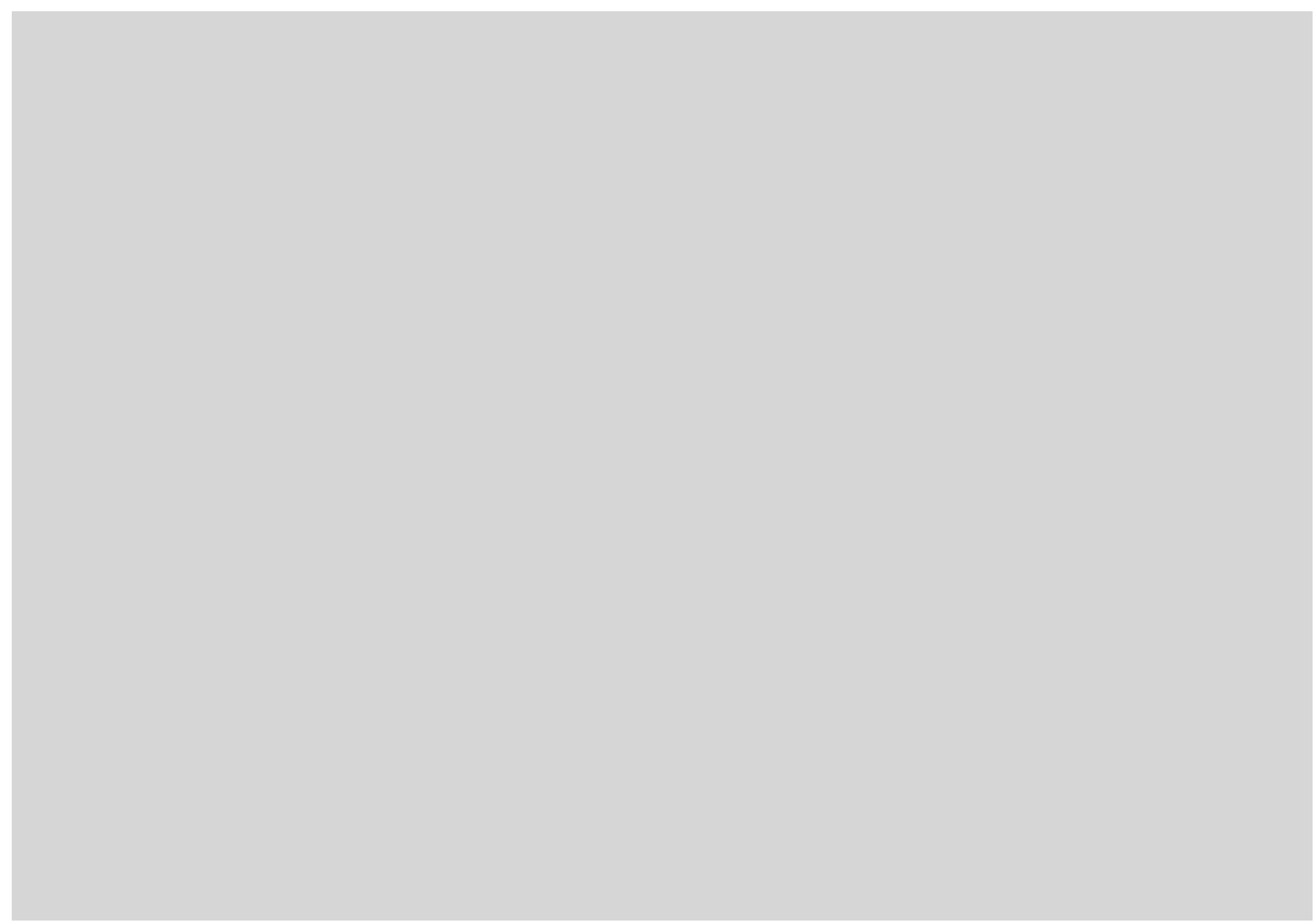


Rechtshistorikers August Traat (1911-2007) jedoch in der Zeit des politisch aktiven Dorpater Bischofs Dietrich Damerow (1379-1400). ${ }^{19}$ Da bei der Formulierung der Punkte der mittelalterlichen Verträge stets faktische Zwischenfälle eine wichtige Rolle spielten, ist es allerdings sehr glaubwürdig, dass der „Baum“ von Warbeck nicht sehr lange Zeit vor dem Abschluss vom „Nieburfrieden“ eingerichtet wurde (oder begann auch die Kaufleute aus Nowgorod zu betreffen). Auch spätere Verträge mit den Russen fordern die Beseitigung von Barrieren, ${ }^{20}$ damit ist aber nicht ihr physischer Abriss gemeint, sondern die Zollfreiheit für Kaufleute. Die Barriere war mit einem Seil oder einer Kette über den Fluss gespannt, ${ }^{21}$ damit Boote und Schiffe hier nicht ohne zu stoppen durchfahren konnten.

Genauer helfen dendrochronologische Untersuchungen, die Zeit der Errichtung der Burg festzulegen. Auf diese Weise kann mit großer Genauigkeit (gewöhnlich ein Jahr) das Alter sehr unterschiedlicher Bauwerke und von Gegenständen aus Holz festgestellt werden. ${ }^{22}$ Von den vom Westufer des westlichen Wallgrabens der Vorburg Warbecks (Abb. 7: 3) im Jahr 2001 ans Tageslicht gekommenen Balken der Uferbefestigung wurden mit einem Zuwachsbohrer 13 Bohrproben gezogen, jede aus einem anderen Balken. Da die Oberflächen der Balken ein wenig verrottet waren, zerfielen ein Teil der Proben in mehrere Stückchen und die Oberfläche einiger Proben zerbröselte. Jeder Probe wurde beim Messen ein Identifizierungscode gegeben..$^{23}$ Bei den Proben wurde unter dem Mikroskop die Breite der Jahresringe vermessen und sie wurden mit den Reihen der Breite von Jahresringen untereinander auf Grafiken verglichen.

19 [Traat], Ajalooline Emajögi, 54.

20 Lietuvos metrika (1427-1506), Knyga nr. 5, hrsg. von Egidijus Banionis (Vilnius: Mokslo ir enciklopedijų leidykla, 1993), Nr. 119.2, 216 (1503). Vgl. Goetz, Deutsch-Russische Handelsverträge, 215

21 „Franz Nyenstaedt's Livländische Chronik nebst dessen Handbuch“, Monumenta Livoniae antiquae, Bd. 2, hrsg. von Gotthard Tielemann (Riga, Leipzig: Frantzen, 1839), 6.

22 Fritz H. Schweingruber, Werner H. Schoch, Holz, Jahrringe und Weltgeschehen (Bern: Mets 1 (2012), 20-25; Alar Län, ,Mida kasulkk ante Dendrokronoloogilise uurimise metoodikast. What Wood Tells Us. On Dendrochronological Research Methodology“" Rode altar lähivaates. Rode Altarpiece in Close-Up, hrsg. von Hilkk Hiiop, Merike Kurisoo (Tallinn: Eesti Kunstimuuseum, 2016), 115-134.

23 Alar Läänelaid, „Tree ring data from Estonia collected in 1999“, Conifer growth variability during the Holocene in Northern Europe. Proceedings of the meeting in Lund, Sweden 16-19 Faculty of Forestry Research Notes, Bd. 108 (Joensuu: Joensuun yliopisto, 2000), 107-117.
Als untereinander ähnliche Reihen gelang es, die Jahresringe dreier Proben in einen mathematischen Durschnitt über eine Länge von 80 Jahren mit einem Code 2epkst07 zu bringen. Wichtig ist zu vermerken, dass alle drei Proben mit dem Jahresring unter der Rinde enden. Dies bedeutet, dass der Jahresring unter der Rinde für diese Bäume der letzte Wachstumsring blieb, danach wurden diese Bäume gefälltt und die Balken wurden für die Errichtung der Uferbefestigung verwendet. Es kann vermutet werden, dass die im Wald geschlagenen Balken ungetrocknet verwendet wurden, denn es machte keinen Sinn, in den Boden einzubringendes Holz vorher zu trocknen. Dies bedeutet seinerseits, dass das Jahr der Bauarbeiten das dem letzten Wachstumsjahr des Jahresrings unter der Rinde folgende war. Bei den anderen, aus den Balken Warbecks gewonnenen Proben sind durch Moder und Zerfall die Jahresringe verloren gegangen, so dass es nicht gelang, ihre Reihe der Breite der Jahresringe untereinander glaubwürdig in einen Durchschnitt zu bringen.

Die durchschnittliche Reihe 2epkst07 der Dicke der Jahresringe der Balkenproben wurde mit der estnischen Kiefernchronologie ${ }^{24}$ mit den Programmen Catras ${ }^{25}$ und TSAP-Win ${ }^{26}$ verglichen, um die Datierung der Warbecker Jahresringe zu ermitteln. Diese Computerprogramme vergleichen zwei Reihen von Jahresringstärken miteinander (die zu untersuchende Reihe und diejenige bekannten Alters), sie verschieben die zu untersuchende Reihe in Beziehung zur Vergleichsreihe jeweils um ein Jahr und berechnen in jeder Position die Ähnlichkeit der Reihen. Voraussichtlich zeigt die Position der größten Ähnlichkeit die Wachstumsjahre der Jahresringe der zu untersuchenden Reihe. Da ein ähnliches Jahresringmuster von Bäumen wegen eines ähnlichen Wetters in der Lebenszeit der Bäume entsteht, dann können so die Kalenderjahre des Wachstums von Bäumen ermittelt werden, darunter das im Leben eines Baums letzte Wachstumsjahr.

Die Balken der Uferbefestigung Warbecks wiesen eine durchschnittliche Jahresringreihe 2epkst07 auf und die erwies sich als

24 Alar Läänelaid, Dieter Eckstein, „Development of a Tree-ring Chronology of Scots Pine Pinus sylvestris L.) for Estonia as a Dating Tool and Climatic Proxy“, Baltic Forestry, 9 (2003), $76-82$

25 Roland W. Aniol, „Tree-ring analysis using CATRAS“, Dendrochronologia 1 (1983), 45-53. 26 Rinntech TSAP-Win. Software for tree-ring measurement, analysis and presentation Product information (Heidelberg), http://www.rinntech.de/images/stories/PDF/TSAPWin_brochure. pdf (letzter Zugriff am 10.04.2017). 


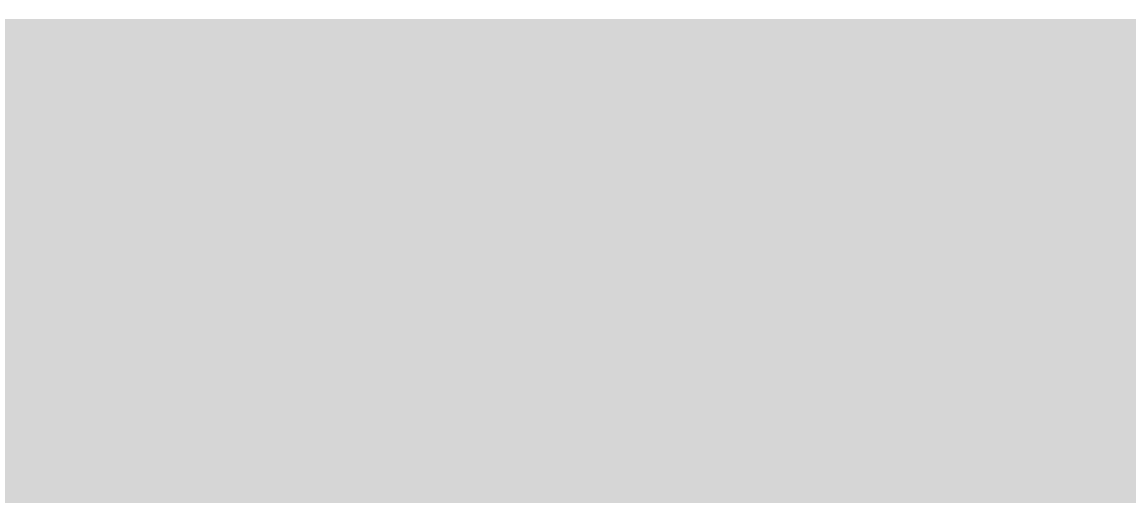

Tabelle 1. Ausdruck der Datierung des Programms TSAP-Win: Die fünf besten Positionen der Jahresringreihe von Warbeck im Verhältnis zur Vergleichschronologie. Gezeig werden die Deckung der Reihen (OVL), verschiedene statistische Ännlichkeitsmerkmale (Glk, TV, TVBP, TVH) und das späteste Jahr der zu untersuchenden Reihe (DateR) im Falle unterschiedlicher Positionen. Die hôchsten Ähnlich Datierung der zu untersuchenden Reihe auf das Jahr 1376

am ähnlichsten mit der Position in der estnischen Kiefernchronologie 3epestcr (AD 1111-2006), bei der die letzte Dicke des Jahresrings der Warbeck-Reihe an der Stelle der estnischen Kiefernchronologie der Stärke des Jahresrings des Jahres 1376 ist (Tabelle 1). Diese Position lässt sich visualisieren als Grafik der Reihe der vergleichenden Jahresringdicke (Abb. 3). Auf der Abbildung sehen wir, dass die wichtigsten Ausschläge der grafischen Linie (besonders die nach unten weisenden, d.h. der engen Jahresringe) an denselben Stellen erfolgen. Die Datierung ergibt, dass die zur Errichtung der Uferbefestigung der Vorburg Warbecks genutzten und untersuchten Balken im Jahr 1376 nach der Wachstumsperiode (im Sommer) gefällt wurden und vor der Wachstumsperiode des Jahres 1377. Diese Datierung ermöglicht es nicht, eine genauere Zeit des Holzeinschlags zu bestimmen. Unter Voraussetzung der Nutzung von ungetrocknetem Holz wurden die Balken wahrscheinlich unmittelbar nach dem Fällen der Bäume in der Anlage eingebaut, spätestens im Sommer des folgenden Jahres. Damit wurde die Uferbefestigung des Wallgrabens der Vorburg Warbecks nach der dendrochronologische Datierung der Baubalken wahrscheinlich im Jahr 1377 errichtet.

Der Bau der Burg durch Bischof Heinrich von Velde (1373-1378) könnte früher geplant worden sein. Dafür könnte der 1367-1371 andauernde Grenzkrieg zwischen Pleskau und dem Bistum Dorpat

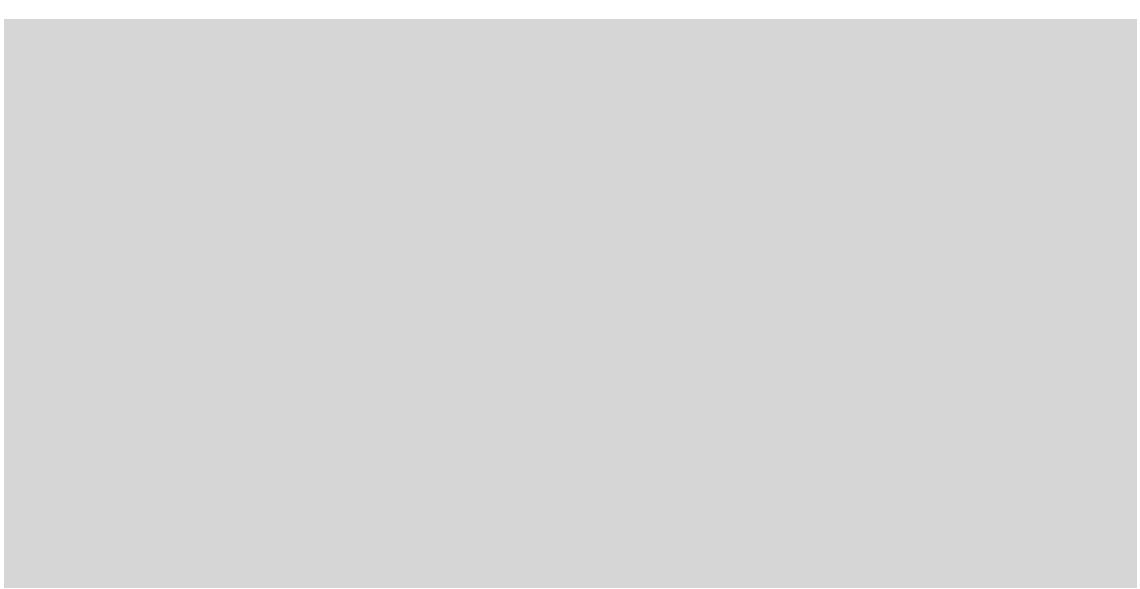

Abb. 3. Die durchschnittliche Reihe der Jahresringdicke 2epkst07 der Holzproben $(8+9+10)$ der drei Balken der Uferbefestigung der Vorburg von Warbeck in synchroner Position mit der estnischen Kiefernchronologie 3epestcr. Die Reihen decken sich im Umfang von der Y-Achse die Dicke der Jahresringe in der Einheit von 0,01 mm.

den Anlass geliefert haben, dessen Hauptschlachtfeld der Peipussee war und als dessen Anlass nämlich Streitereien um Fischfangrechte im Bereich des Warmen Sees (est. Lämmijärv, russ. Teploe ozero) erwähnt wurden. ${ }^{27}$ Der in Neuhausen (Vastseliina) geschlossene Frieden bekräftigte, dass die Parteien „sich an ihre Grenzen und Ländereien beim Fischfang, den Gewässern und anderen Dingen so wie früher" halten, ${ }^{28}$ aber es ist klar, dass sich eine Burg möglichst nah am Seengebiet zum Bewahren der Positionen des Bistums als zwingend notwendig erwies. Weiterhin, im Jahr 1377 kam der Sohn des litauischen Großfürsten Algirdas (gest. am 28. Mai 1377), Andre (etwa 1320-1399), nach Pleskau. ${ }^{29}$ Unmittelbar zuvor hatte Andrei an den Grenzen Livlands in Lettgallen Krieg geführt, seine Besteigung des Fürstenthrons könnte das Bistum zu Befestigungsarbeiten zwingen.

27 Stern, „Dorpat-Pleskauer Kämpfe“, 117-123

28 „Hermanni de Wartberge Chronicon Livoniae“, hrsg. von Ernst Strehlke, Scriptores rerum prussicarum. Die Geschichtsschreiber der preussischen Vorzeit, Bd. 2, hrsg von Theodor Hirsch u. a. (Leipzig: Hirzel, 1863), 9-178, 802-803, hier 98 .

29 Pskovskie letopisi, Bd. 1, hrsg. von Arsenij N. Nasonov (Moskau, Leningrad: Izdatel'stvo Akademii nauk SSSR, 1941), 24; Pskovskie letopisi, Bd. 2, 105-106. 
Der Burggraf von Warbeck verfügte im 16. Jahrhundert über die Vollmacht, sämtliche Schiffe und alle über Land, Wasser oder Eis zu transportierenden Waren zu kontrollieren. Hier wurde auch die Einhaltung des gegen die Russen gewandten Handelsembargos (militärisches Gerät, zeitweilig Getreide) kontrolliert. ${ }^{30}$ Der finnische Ethnologe Kustaa Vilkuna (1902-1980) setzte Warbeck in eine Reihe mit den sogenannten "Sperrburgen“ in Skandinavien und Russland, dies sind am Wege liegende Wachtürme mit Zollpunkten. Er bekräftigte auch, dass wahrscheinlich die Grundlage des estnischen Ortsnamens Kastre ein Wort altrussischer Etymologie war (костеръ, koster") und dieses in den östlichen ostseefinnischen Sprachen Burg oder Festung bedeutet. ${ }^{31}$ Darauf hatte wissenschaftlich begründet bereits Julius Mägiste verwiesen (1900-1978). ${ }^{32}$ Костерь heißt im Altrussischen auch einfach Burgturm. ${ }^{33}$ An den Unterlauf des Embach kann dieser Ortsname auch durch die Vermittlung der Woten gelangt sein. ${ }^{34}$ Diese Vermutungen können auch durch archäologische Funde Unterstützung finden: Aus dem Bereich des Unterlaufs des Embach sind nämlich drei aus dem 13.-15. Jahrhundert stammende Dorffriedhöfe mit Grabbeigaben wotischer Art bekannt. Am dichtesten an der Burg Warbeck liegt derjenige in Mäxhof, im Norden

30 „Franz Nyenstaedt's Livländische Chronik“, 6.

31 Kustaa Vilkuna, „Missä sijaitsi Oulun ensimmäinen linna ja mitä olivat kastarit eli salpalinnat?“, Suomalainen Tiedeakatemia. Esitelmät ja pöytäkirjat 1973 (1975), 138-171, hie 149-152; Kustaa Vilkuna, „Über mittelalterliche Sperrschlösser an Handelswegen im Baltikum und in Finnland“", Häuser und Höfe der handeltreibenden Bevölkerung im Ostseegebiet und im Norden vor 1500. Beiträge zur Geschichte und Soziologie des Wohnens. Acta Visbyensia, Bd. 5 (Visby: Gotlands Fornsal, 1976), 191-202, hier 192; Felix Oinas, „Kastre nimest“, Tulimuld, 1 (1979), 54. Der Ortsname wurde auch mit dem lateinischen Wort castrum (Burg) in Verbindung gebracht: Löwis of Menar, „Die Ruine der Deutschordensvogtei“, Nr. 265; Laur Kettunen, Etymologische Untersuchung über estnische Ortsnamen. Suomalainen Tiedeakatemian Toimituksia Serie B, Bd. 90/1 (Helsinki: Suomalainen tiedeakatemia, 1955), Nr. 513, 178; Edga Valter Saks, „Kastre pole vene nimi““, Tulimuld, 2 (1978), 111.,„Wõnnu kihelkonna kohanimed“, Pühapäevaleht, Nr. 42 (47), 20.10.1929, 4, hielt die Anfangsform des Ortsnamens für aus dem Kloster ab: Stern, .Die bischöfliche Embachfestung"“ 47 . Jaak Siim schloss auch die Möglichkei der Ableitung vom deutschsprachigen Nachnamen Koster, der seinerseits vom Wort koster (Köster) kommen könnte, nicht aus: Jaak Simm, ,Vene elemente Võnnu asulanimedes“", Eesti NSV Teaduste Akadeemia Toimetised. Ühiskonnateadused, 21 (1972), 287-299, hier 288-289; Jaak Simm, Keelearheoloogilist kohanimede alalt"“, Keel, mida me uurime, hrsg. von Mar Mäger (Tallinn: Valgus, 1976), 102-105, hier 103-104.

32 Julius Mägiste, „Zu einigen fraglichen alten ostseefinnischen Lehnwörtern aus dem Russischen“, Slaviska Institutionen vid Lunds Universitet Årsbok 1953-1954 (Lund, 1954), $19-65$, hier $40-50$

33 Siehe zum Beispiel: Pskovskie letopisi, Bd. 2, 109, 353.

34 Aliise Moora, Peipsimaa etnilisest ajaloost (Tallinn: Eesti Riiklik Kirjastus, 1964), 63. des Kreises Dorpat sind solche die Friedhöfe in Wälgi (Välgi) und Kusma. ${ }^{35}$ Der mittelniederdeutsche Name war Warbek, die verbreitete Erklärung dafür ist, dass Werbek nämlich „Verteidigung des Flusses “/36 (mittelniederdeutsch were des bekes) bedeute. Parallel dazu wurde auch in den zeitgenössischen deutschsprachigen Niederschriften der Ortsname Castor, Kaster verwendet. ${ }^{37}$

Doch were bedeutete gleichzeitig auch in den mit dem Bistum Dorpat verbundenen Quellen vor allem ein Fischwehr, eine quer durch den Fluss eingebaute Anlage zum Fangen von Fischen. ${ }^{38}$ Allgemeine Vorbedingung für den Aufbau von solchen Anlagen war, dass sie nicht den ganzen Fluss schließen sollten. Im Jahre 1224 teilte der Bischof von Dorpat seinen Machtbereich mit dem Schwertbrüderorden derart auf, dass dem letzterem Sackala (Sakala), Nurmegunde (Nurmekund), Mocha und ein Teil von Waigel (Vaiga) verblieb. ${ }^{39}$ Im Vertrag und in dessen zehn Jahre jüngerer Ergänzung ${ }^{40}$ wird von den Fischfangrechten des Ordens auf dem Embach (Emaioga) geredet, wobei Fischwehren nicht über mehr als die Hälfte des Flusses herausragen durften. Um welchen Ort es ging, ist unklar, doch als Orientierung ist im jüngeren Dokument die via Ruthenorum, der „Weg der Russen“ erwähnt. Wahrscheinlich ist hier die Rede von der Grenze Sackalas am Kleinen Embach (Väike Emajõgi), ${ }^{41}$ doch der Vertrag belegt dennoch die allgemeine Rechtspraxis.

In der Übereinkunft der Stände des Bistums Dorpat vom Jahr 1458 wird unter Androhung einer Strafe gefordert, dass bezüglich von Fischwehren ein Drittel des Flusses geöffnet sein müsse und besonders bei Warbeck müssten die Wehren ausreichend aufgesperrt

35 Priit Ligi, Heiki Valk, ,Vadjapärased kalmistud Tartumaal (13.-15. sajand)“, Vadjapärased kalmed Eestis 9.-12. sajandil, hrsg. von Valter Lang. Muinasaja Teadus, Bd. 2 (Tallinn: Teaduste Akadeemia Kirjastus, 1993), 176-214

36 Beispielsweise Löwis of Menar, Burgenlexikon, 120; Paul Johansen, Kaugete aegade sära (Tartu: Ilmamaa, 2005), 37, 439.

37 Siehe auch: Marje Joalaid, „Kastre“, Eesti kohanimeraamat, hrsg. von Peeter Päll, Marja Kallasmaa (Tallinn: Eesti Keele Sihtasutus, 2016), 184.

38 Siehe: Gustav Ränk, Peipsi kalastusest. Õpetatud Eesti Seltsi Kirjad, Bd. 2 (Tartu: Õpetatud Eesti Selts, 1934), 129-155.

39 Liv-, Esth- und Curländisches Urkundenbuch nebst Regesten, Bd. 1, hrsg. von Friedrich Georg von Bunge (Reval: Kluge und Ströhm, 1853), Nr. 62. Siehe auch: Monumenta Livoniae und Aufsätzen, Bd. 3, hrsg. von Carl Julius A. Paucker (Riga, Leipzig: Frantzen, 1842), 144.

40 Liv-, Esth- und Curländisches Urkundenbuch, Bd. 1, Nr. 140

41 Siehe: Johansen, Kaugete aegade sära, 19 
sein, so dass ein Flussschiff unbehindert durchfahren könne. ${ }^{42}$ Darum könnte die Herkunft des mittelniederdeutschen Ortsnamens weniger durch die militärische Absperrung des Flusses erklärt werden, als vielmehr mit dem Fischfang. ${ }^{43}$ Die Bedeutung Warbecks als Zentrum des mittelalterlichen Fischfangs am Unterlauf des Embachs und auf dem Peipussee war sehr groß. Beim „Baum“ von Warbeck wurde der Zehnt von den Fischen genommen, welche die Dorpater von den Undeutschen - das sind die örtlichen Bauern - kauften. Eine besondere Ordnung galt für die Besteuerung der von Russen gekauften Fische. Von Undeutschen durften getrocknete Fische erst erworben werden nachdem sie ihren Zehnt entrichtet hatten. Wenn jemand selbst Fische trocknen wollte, dann musste dies beim „Baum“ von Warbeck geschehen, aus Russland gekaufter Fisch war aber am "Strand“ zu trocknen. ${ }^{44}$ Damit fungierte Warbeck auch als Grenzpunkt für den Fischhandel, bei dem die Grundlage für die Besteuerung der Transport der Fische vom Peipussee und vom Mündungsgebiet des Embachs in das Binnenland des Bistums war. ${ }^{45}$ Als Dorpat 1558 in die Hände der Russen fiel, bekräftigte auch Zar Ivan IV. (1530-1584) die Bedeutung Warbecks für den Fischhandel am Embach in dem der Stadt verliehenen Privileg: Die zwölf rumeniki (Fischhändler) Dorpats konnten in alter Weise Fische von den Pleskauern kaufen, doch einen Zehnt mussten sie in Warbeck nicht entrichten. Beim Fischen in Warbeck und an anderen Orten musste aber der Zehnt bezahlt werden. ${ }^{46}$ Den Fischzoll Warbecks aus der Zeit des Bistums erinnerte man noch selbst im 18. Jahrhundert. ${ }^{47}$

42 Akten und Rezesse der livländischen Ständetage, Bd. 1, hrsg. von Oskar Stavenhage .

43 Siehe auch: Monumenta Livoniae Antiquae, Bd. 3, 9.

44 Akten und Rezesse, Bd. 1, Nr. 649 \$ 9. Vgl. Akten und Rezesse der livländischen Ständetage, Bd. 3, hrsg. von Leonid Arbusow (Riga: Deubner, 1910), Nr. 166 §6; 237 §3.

45 „Franz Nyenstaedt's Livländische Chronik“, 6. Vgl. Friedrich Konrad Gadebusch, Livländische Jahrbücher, Bd. 1/2 (Riga: Hartknoch, 1780), 416-417.

46 Dopolnenija k Aktam istoričeskim, otnosjaščimsja k Rossii. Sobrannye v inostrannych (S) Vgl. die unterschiedlich v pervye gody Livonskoj vojny (novye dokumenty)“. Peterburgskie slavjanskie i balkanskie issledovanija, 1 (2008), 77-88, hier 81, danach kann vermutet werden, dass der Zehnt auf alle Fälle entrichtet werden.

47 August Wilhelm Hupel, Topographische Nachrichten von Lief- und Ehstland, Bd. 1 (Riga: Hartknoch, 1774), 263.
Die Fanggründe des Embachs und seines Mündungsgebiets gehörten nicht nur dem Bistum. Im Verwaltungsgebiet Warbecks sowohl auf dem Embach, auf den Flüssen und den Seen des Embach-Deltas als auch auf dem Peipussee lagen die Fanggründe des Dorpater Bischofs, des Domkapitels, der Stadt Dorpat, der Klöster und der privaten Gutshöfe, ebenso auch die des Deutschen Ordens. ${ }^{48} \mathrm{Im}$ 17. Jahrhundert wurde der hiesige Fischreichtum gelobt, besonders der von Brasche, Hecht und Aland. Aus dem Mittelalter stammen die Bezeichnungen der damals registrierten Fanggründe wie ,Bischofsfang' (Bieschofszug), ,Mönchsuntiefe (Muncka parre) $)^{49}$ und andere. ${ }^{50}$ Das im Mittelalter zum Kloster Falkenau gehörige Gut Fölk (Laatre) benutzte auch im 17. Jahrhundert noch in der Nähe Warbecks gelegene Fanggründe. Sie hieß Mukelon, ${ }^{51}$ d.h. „Muugaloom" auf Estnisch, ,Fanggrund der Mönché.

Warbeck war also an der Grenze des Bistums Dorpat. Der Weg über Land nach Warbeck führte bei Oldenthorn entlang. ${ }^{52}$ Der Wasser- oder Winterweg (wenn der Fluss zugefroren war) stellte eine wichtige Verbindungsader dar und führte durch Warbeck von Dorpat nach Russland oder nach Narwa (Narva). Im Jahr 1438 reiste die Delegation der Russischen Kirche unter Leitung des Metropoliten Isidor von Kiew, eines Griechen, hier entlang nach Italien zum ökumenischen Konzil, welches die Vereinigung der lateinischen mit der griechischen Kirche erörterte. Nachdem sich die in Moskau ihre Reise begonnene Gesandtschaft sieben Wochen lang in Pleskau aufgehalten hatte, setzte sie am 22. Januar auf dem Winterweg des Peipussees ihre Reise durch Livland fort. Ein anonymer Reisebegleiter des Metropoliten beschrieb die Ankunft

48 Die Revision Livlands 1601. Estnisches Siedlungsgebiet, hrsg. von Oleg Roslavlev. Hefte zur Landeskunde Estlands, Bd. 3 (Wolfratshausen-Waldram: Roslavlev, 1967), 3-12; Selart, Eesti idapiir, 90

49 Oder auch ,Mungapurre‘, eine Fischsperre wurde auf Estnisch auch als ,purre“ (Steg) bezeichnet: Ants Viires, „Kalatõoked Eesti jõgedel“, Eesti Loodus, 3 (1982), 177-182, hier 181.

50 Das Dorpater Land 1624/27, hrsg. von Oleg Roslavlev. Hefte zur Landeskunde Estlands, Bd. 1 (Wolfratshausen-Waldram: Roslavlev, 1965), 43-44; „Franz Nyenstaedt’s Livländisch Chronik", 6 .

51 Liivimaa 1638. a. maarevisjon. Eesti asustusala I: Kaguosa. ENSV Riigi Keskarhiivi Tartu osakonna toimetused, Bd. 1 (7) (Tartu: Teaduslik Kirjandus, 1941), 12.

52 Livländische Güterurkunden. Aus den Jahren 1501 bis 1545, Bd. 2, hrsg. von Herman von Bruiningk (Riga: Gulbis, 1923), Nr. 17, 14 
im Bistum Dorpat folgendermaßen: „Die erste deutsche Burg ist die des Bischofs von Dorpat, Warbeck (Kocnupъ, Kospir"'). Und hier nahm ihn [den Metropoliten] der Dorpater Bischof nach seinem deutschen Brauch mit großer Ehrerbietung, mit Posaunen und Flöten in Empfang und erwies ihm große Ehre und gab viele Geschenke. Aber von Pleskau bis zur Stadt Dorpat sind es 100 Werst. " ${ }^{53}$ Hohe Gäste wurden an der Grenze empfangen, damit war Warbeck eine wirkliche Grenzburg. Im Jahr 1538 erwartete der russische Gesandte gerade in Warbeck die Antwort des Bischofs von Dorpat in der Frage der Auslieferung des aus Russland geflüchteten italienischen Baumeisters Peter Hannibal. ${ }^{54}$

Warbeck war im Bistum Dorpat das Zentrum eines Verwaltungsbezirks. Der hiesige Burggraf ${ }^{55}$ sollte ein ausgesprochen großes Territorium administrieren, zu dem auch Koddafer (Kodavere), Borka (Piirisaar) und das Seegebiet gehörte. Das Bischofsgut Warbeck existierte nach Herbert Ligis (1928-1990) Vermutung bereits im 13. Jahrhundert, also vor der Errichtung der Burg. ${ }^{56}$ Zum Gutshof gehörten auch Mühlen. ${ }^{57}$ Mehrere Mal hielten sich in der Grenzburg verschiedene Bischöfe Dorpats auf, deshalb mussten sich an der Burg auch angemessene Räumlichkeiten finden lassen. Im März und Juli 1425, im März 1433 und im November 1439 hielt sich der

53 Natal'ja A. Kazakova, „Pervonačal'naja redakcija „Choždenija na Florentijski sobor'““, Trudy Otdela drevnerusskoj literatury, 25 (1970), 60-72, hier 63. Vgl. Europa im XV. Jahrhundert von 153. Siehern gesehen. Byzantinische Geschichtsschreiber, Bd. 2 (Graz, Wien, Köln: Styria, 1954), die Union von Florenz (1439)“" Zeitschrift für Historische Forschung, 36 (2009), 1-32, hier 6 . 54 Jüri Kivimäe, „Pjotr Frjazin või Peter Hannibal? Itaalia arhitekt hiliskeskaegses Moskvas ja Tartus“, Tartu - minevik, tänapäev, hrsg. von Jüri Linnus (Tallinn: ENSV Teaduste Akadeemia, 1985), 97-108, hier 107-108.

55 Liv-, Est-und Kurländisches Urkundenbuch, Bd. 12, hrsg. von Philipp Schwartz, August von Bulmerincq (Riga, Moskau: Deubner, 1910), Nr. 143; Leonid Arbusow, „Livlands Geistlichkeit vom Ende des 12. Jahrhunderts bis ins 16. Jahrhundert. Dritter Nachtrag", Jahrbuch für Genealogie, Heraldik und Sphragistik 1911, 1912 und 1913 (1914), 1-432, hier 317. Vgl. Axel von Gernet, Verfassungsgeschichte des Bisthums Dorpat bis zur Ausbildung der Landstände. Verhandlungen der Gelehrten Estnischen Gesellschaft zu Dorpat, Bd. 17 (Jurjew: Schnakenburg, 1896), 127, Pärtel Piirimäe, „Tartu piiskopkonna võimustruktuuridest Vana-Liivimaa lõpusajandil“, Tartu, altisakslased ja Saksamaa, hrsg. von Helmut Piirimäe, Claus Sommerhage (Tartu: Tart Ülikooli Kirjastus, 1998), 33-52, hier 44

56 Herbert Ligi, Eesti talurahva olukord ja klassivõitlus Liivi sõja algul (1558-1561) (Tallinn: Eesti NSV Teaduste Akadeemia, 1961), 364.

57 Livländische Güterurkunden, Bd. 2, Nr. 638, 383-384; Polnische Akten I: 1582-1591, hrsg. von Oleg Roslavlev. Hefte zur Landeskunde Estlands, Bd. 5 (München: Roslavlev, 1970), 116. Siehe auch: Livländische Güterurkunden, Bd. 2, Nr. 682, 418
Dorpater Bischof Dietrich Resler (1413-1441) in Warbeck auf. ${ }^{58}$ Gerade er begrüßte hier auch den Metropoliten Isidor. Erhältlich sind die nach Reval gesandten Briefe des Bischofs, der unter anderem in Bologna studiert hatte und für einige Zeit in Rom bei der Kurie aktiv war, ${ }^{59}$ sie sind gezeichnet ", auf unserer Burg zu Warbeck" (up unsem slote to Werbeke). Quellen der mittelalterlichen Geschichte Dorpats sind nur wenige überliefert, doch unter jenen Bruchstücken fällt der Aufenthalt Bischof Dietrichs in Warbeck auf. Ansonsten residierte der ältliche Bischof zumeist in Dorpat, in der Regel unternahm er nur in Verbindung mit den Landtagen Reisen nach Walk (Valga) oder auch nach außerhalb seines Bistums. Von den Burgen des Stifts Dorpat hat er sich in Kirrumpäh (Kirumpää), Neuhausen und Oldenthorn aufgehalten sowie im Kloster Falkenau. Auf jeden Fall befand sich Warbeck ungeachtet von den geringeren Ausmaßen in einer vergleichbaren Position mit den anderen Bischofburgen - die mittelalterliche Landesherrschaft setzte ein beständiges Herumreisen im eigenen Fürstentum voraus. ${ }^{60} \mathrm{Im}$ Jahr 1450 ordnete der Lübecker Bürger Hans Heykamp mit seinem Testament die Durchführung einer ganzen Reihe von Wallfahrten an, unter denen wird auch eine erwähnt, die von Dorpat nach Warbeck durchzuführen war. ${ }^{61}$ Auf Basis dieser knappen Information kann vermutet werden, dass die Kapelle der Burg (oder der Siedlung) das im Spätmittelalter gewöhnliche Indulgenzprivileg erworben hatte, demgemäß zu einem

58 Liv-, Est- und Curländisches Urkundenbuch, Bd. 7, hrsg. von Hermann Hildebrand (Riga Moskau: Deubner, 1881), Nr. 257, 323; Liv-, Est- und Curländisches Urkundenbuch, Bd. 8, hrsg. von Hermann Hildebrand (Riga, Moskau. Deubner, 1884), Nr. 674; Liv-, Est- und Curländisches Urkundenbuch, Bd. 9, hrsg. von Hermann Hildebrand (Riga, Moskau: Deubner, 1889), Nr. 391

59 Brigide Schwarz, „Alle Wege führen über Rom. Eine „Seilschaft“ von Klerikern aus Hannover im späten Mittelalter“, Hannoversche Geschichtsblätter, 52 (1998), 5-87.

60 Vgl. Vasilij V. Dorošenko, Očerki agrarnoj istorii Latvii v XVI veke (Riga: Izdatel'stvo AN LSSR, 1960), 18; Klaus Neitmann, ,Rat und Ratsgebietiger Wolters von Plettenberg. Beobachtungen zum Regierungs- und Verwaltungsstil des Ordensmeisters“, Wolter von Plettenberg und das mittelalterliche Livland, hrsg. von Norbert Angermann, Ilgvars Misāns Schriften der Baltischen Historischen Kommission, Bd. 7 (Lüneburg: NOKW, 2001), 85-111, hie 95, vgl. 102-111; Klaus Neitmann, „Die Auswahl des Residenzortes. Methodische Bemerkungen zur spätmittelalterlichen geistlichen Residenzbildung ", Spätmittelalterliche Residenzbildung in Heimann (Berlin: Lukas, 2009), 41-88.

61 Carl Fr. Wehrmann, „Der Memorienkalender (Necrologium) der Marien-Kirche in Lübeck“, Zeitschrift des Vereins für Lübeckische Geschichte und Altertumskunde, 6 (1892), 49-160, hier 60. Im Text des Artikels wird an dieser Stelle erwähnt, dass es dem Dorpater Bischof gefiel, sich in Warbeck aufzuhalten. Leider hat der Autor keinen Verweis auf eine Quelle hinzugefüg und deshalb erscheint es als unklar, ob sich die entsprechende Bemerkung bereits im Testamen findet oder ob es sich um eine Hinzufügung des Historikers handelt. 


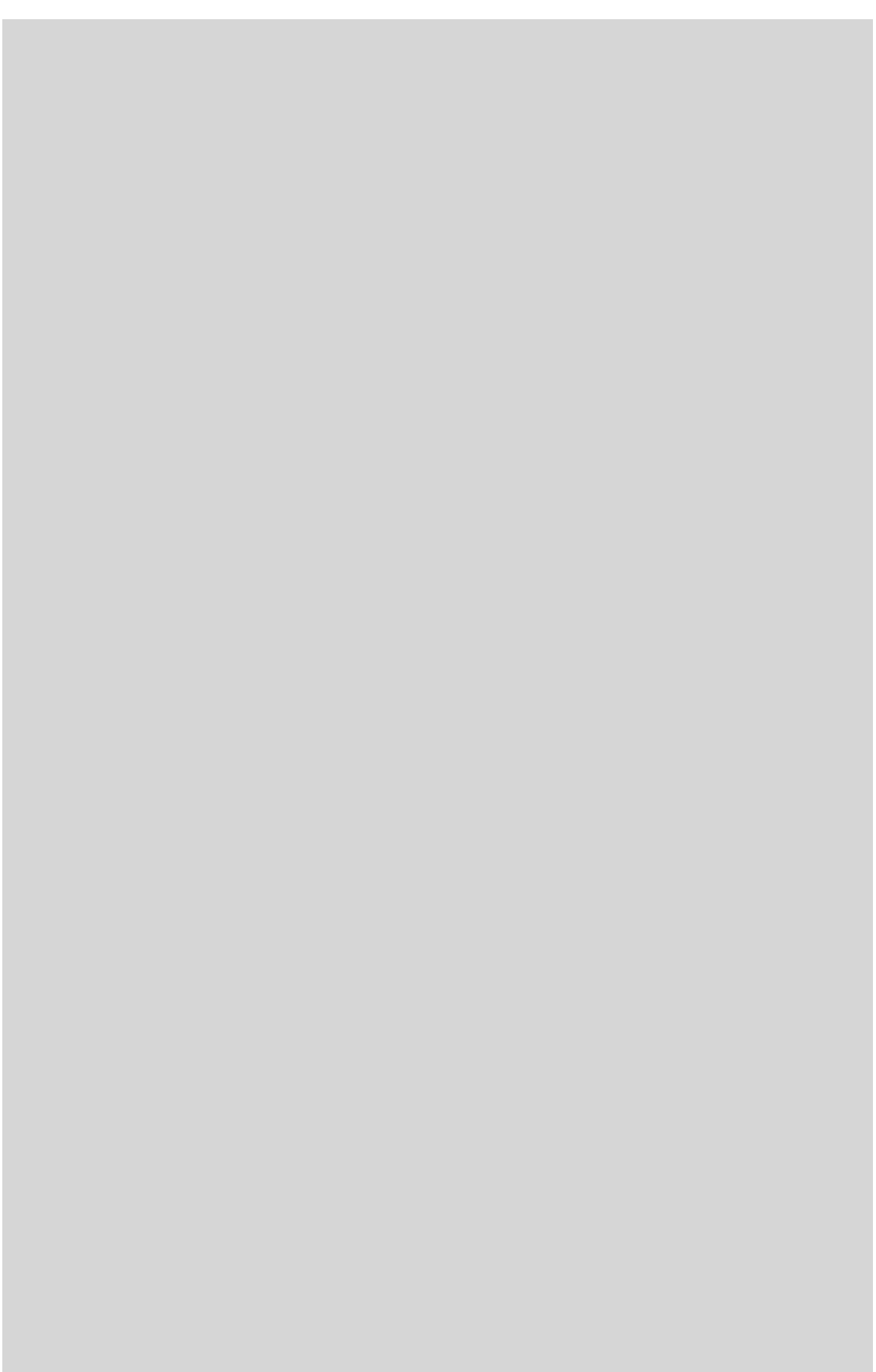

Abb. 4. Lageplan der Burg Warbeck aus dem Jahr 1698 zusammen mit den Abschnitten des Embachs und des Wallgrabens. Schwedisches Staatsarchiv, Militärarchiv (Krigsarkivet), Stockholm

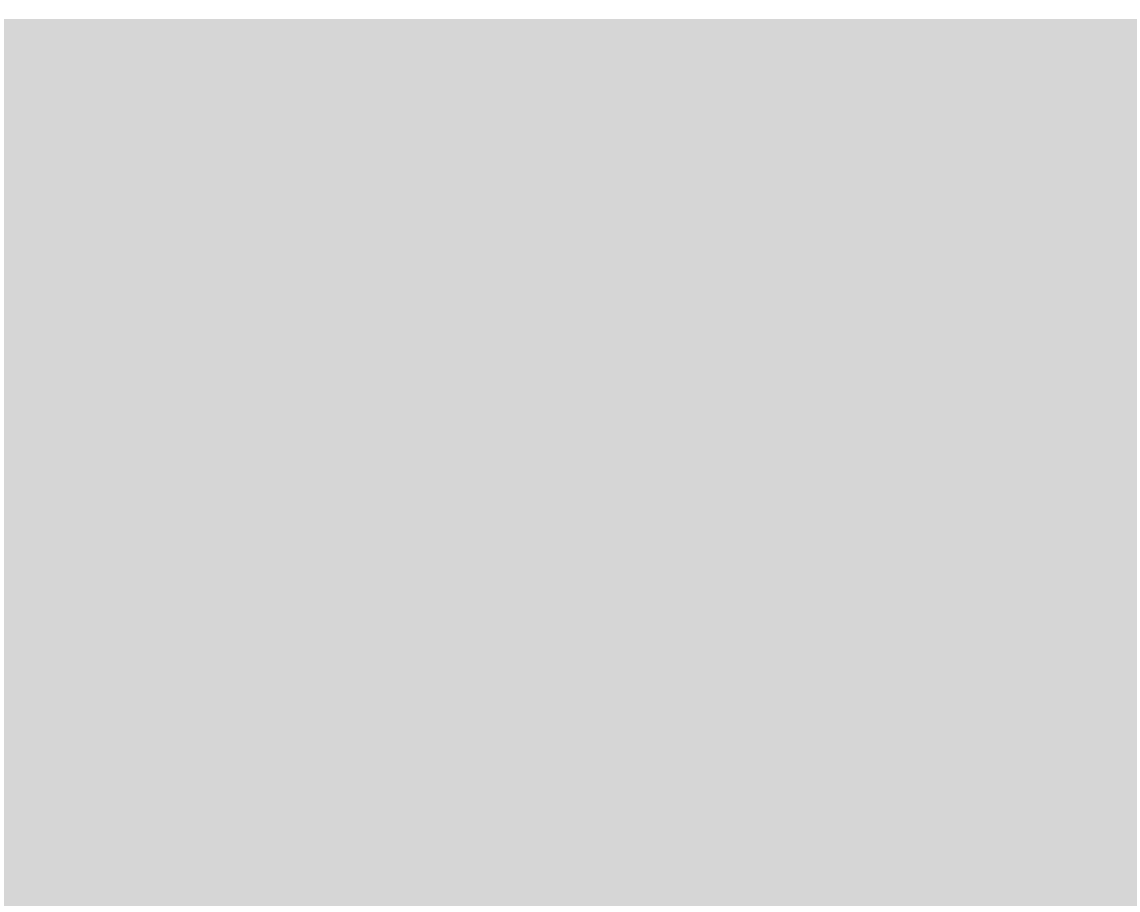

Abb. 5. Grundriss der Burg Warbeck aus dem Jahr 1697. Die allgemeinen Proportionen des Plans sind verschoben. Schwedisches Staatsarchiv, Militärarchiv (Krigsarkivet), Stockholm.

bestimmten Feiertag oder an mehreren deren Besucher in einem vorgegebenem Umfang einen Ablass seiner Sündenstrafen erhielt.

Die Burg musste deshalb auch bei Bedarf angemessen sein, um den Bischof und wenigstens seine notwendige Begleitung unterzubringen. Eine Vorstellung von der Burg verschaffen vor allem deren Pläne aus der schwedischen Herrschaftszeit (Abb. 4 und 5). Bei den archäologischen Ausgrabungen im Jahr 2001 gelang es, nur einen Teil des Gebiets der Burg zu untersuchen. Ohne den Plan von 1697 (Abb. 5) wäre es unmöglich gewesen, auf Basis der in den Gruben und Schächten freigelegten Mauern den Grundriss der Burg zu rekonstruieren. Mit Hilfe des Vergleichs der Grabungsergebnisse ist dies dennoch möglich. Es sollte bemerkt werden, dass die Ausmaße der Burg auf den historischen Plänen im Allgemeinen korrekt sind, doch die Form der Bestandteile der Burg und die Proportionen unterscheiden sich ein wenig von der Realität. Offenbar wurden beim 


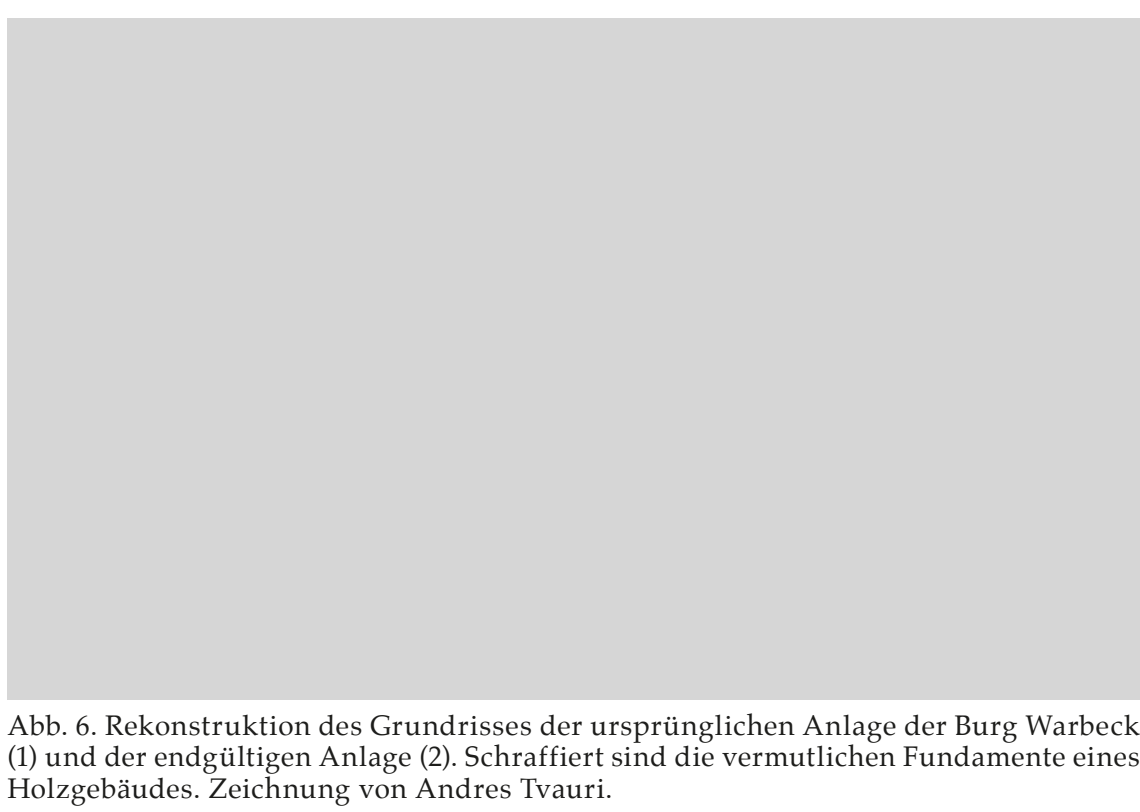

Anlegen des Plans nur die Längen vermessen und wahrscheinlich kein Theodolit verwendet.

Die Burg Warbeck wurde wenigstens in zwei Abschnitten gebaut (Abb. 6). Der erste ist ein Gebäude aus Feldsteinen und Backsteinen $(30-31 \times 15-15,5 \times 10 \mathrm{~cm})$ mit einer unregelmäßigen viereckigen Form (Abb. 6: 1), dessen längste Seite 17,5 m und die kürzeste $12 \mathrm{~m}$ lang war, und die Dicke der Mauern betrug 2,5-2,8 m. Es handelte sich für seine Zeit um ein äußerst kapitales Steingebäude. Zum Vergleich sei gesagt, dass beispielsweise die Stärke des unteren Teils der Dorpater mittelalterlichen Stadtmauer abhängig von der Stelle im Zwischenraum von 1,7-2,9 m bleibt ${ }^{62}$ und die Dicke der Außenwand des Konventhauses der Ordensburg Fellin (Viljandi) in der Höhe des Sockels 2,3 m beträgt. ${ }^{63}$ In diesem Fall befindet sich im östlichen Teil der Nordwand, die von der vermutlichen ursprünglichen Anlage der Burg gesäubert ist, eine 3,1-4 m breite Vertiefung. Diese wurde nicht im Verlauf des Abbruchs der Burg erzeugt, denn beide Seiten der

62 Rivo Bernotas, „Medieval town wall of Tartu in the light of recent research“, Estonian Journal of Archaeology, 15 (2011), 56-72.

63 Andres Tvauri, „Arheoloogilised uuringud Viljandi linnuses 1998. aastal“, Viljand Muuseumi aastaraamat 1998 (Viljandi: Viljandi Muuseum, 1999), 20-27, hier Bild 1.

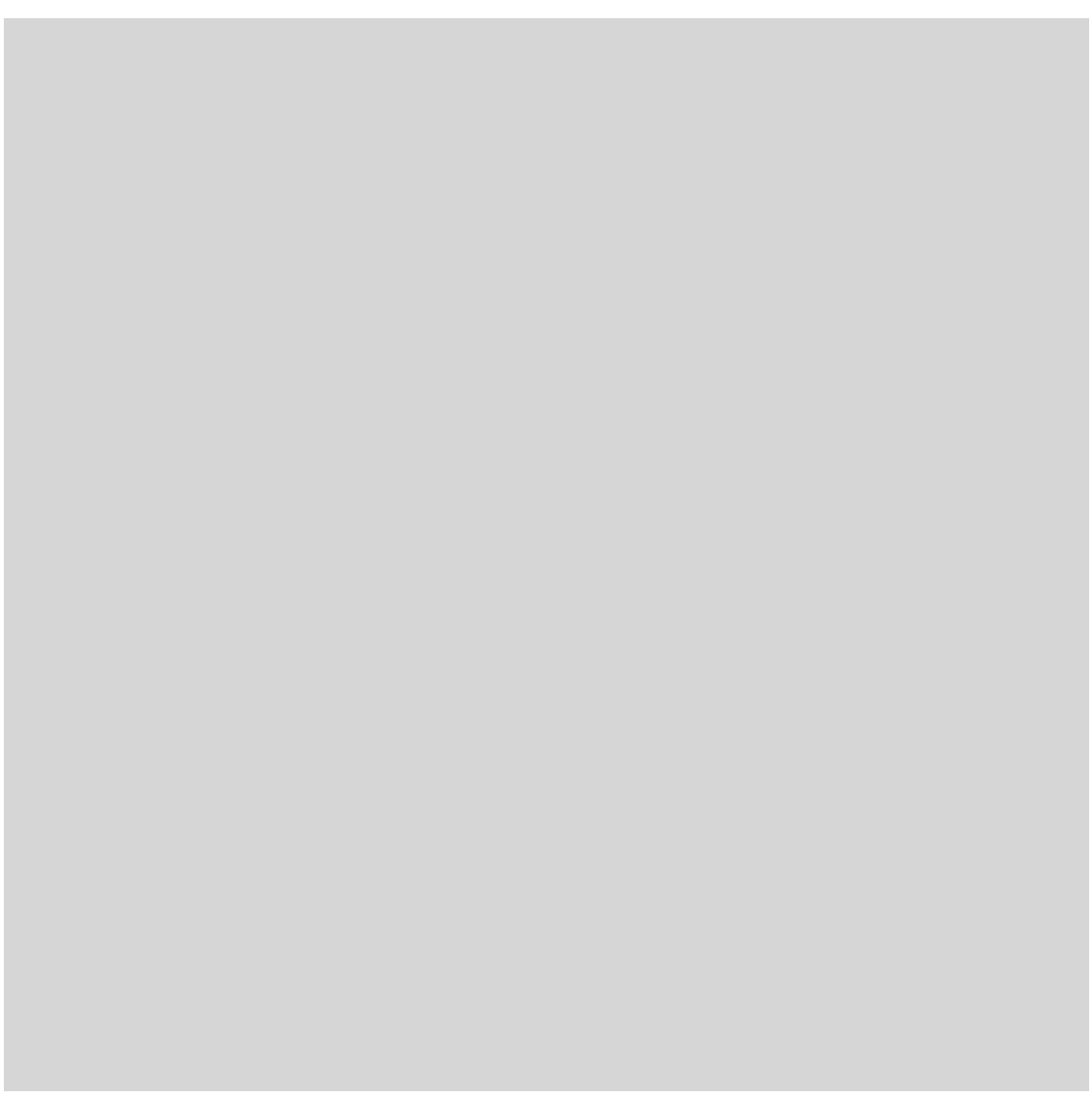

Abb. 7. Bodenprofil des ausgehobenen Schachts an der Ostseite der ursprünglichen Anlage der Burg Warbeck. Zeichnung von Andres Tvauri.

Vertiefung sind mit Ziegelsteinen ordentlich ausgeformt. Möglich, dass hier eine Tür- oder Toröffnung war. Wie dieser nach dem Bau in der südöstlichen Außenecke angelegte Schacht zeigte (Abb. 7), war die Mauer auf Balken errichtet, die sich ihrerseits auf breitere Balkenunterlagen stützen. In einem halben Meter außerhalb der Mauer befand sich eine Wand aus bearbeiteten Balken, die sich ebenfalls auf eine Balkenunterlage stützte. Die Abstände zwischen den Balken waren mit Moos abgedichtet und der Zwischenraum zwischen Mauer und Balkenwand war mit Lehm gefüllt. Im Inneren des Gebäudes befand sich auf der Balkenunterlage eine etwa einen halben Meter dicke Schicht Flusssand, in dem eine bis zu $10 \mathrm{~cm}$ dicke, einheitlich Lehmschicht war. Der Lehm sollte das Eindringen 
von Feuchtigkeit in das Innere des Gebäudes und in die Mauern verhindern sowohl direkt von der Erdoberfläche als auch zurzeit von Überschwemmungen.

Die Mauern des Nord- und Nordwestteils der Burg wurden später gegen die Mauern dieser anfänglichen Anlage errichtet (Abb. 6: 2). Dabei wurden die oberen Bereiche der Nord- und Ostmauer der ursprünglichen Burg abgerissen. Das Mauerwerk des Anbaus ist überwiegend aus Feldsteinen gemauert, nachlässig, mit uneinheitlicher Dicke und verschiedenem Mörtel. Für die Mauern des zweiten Bauabschnitts war ebenfalls eine Balkenunterlage errichtet worden, doch die mit Mörtel verbundenen Mauern waren nicht direkt auf die Balken gebaut worden (wie die Mauern des früheren Bauabschnitts), sondern auf eine Füllschicht aus Feldsteinen und Sand. In den Mauern des Anbaus wurden im Vergleich zu den Mauern des früheren Bauabschnitts Backsteine mit etwas anderen Maßen verwendet $(31 \times 14,5 \times 8-10 \mathrm{~cm})$ und der genutzte Kalkmörtel verfügte im Vergleich zur Ausgangsanlage über einen geringeren Kalkanteil. Der Zwischenbereich der Mauern des Anbaus war mit einer 0,6-1,5 m dicken Füllschicht aus Feldsteinen und Flusssand gefüllt, in der sich auch Backstein- und Mörtelstücke, Tierknochen und Splitter von Keramikgefäßen finden ließen. Zwischen den Mauern der Füllschicht, sowohl in den Innenräumen als auch im Bereich des vermuteten Hofs, war ein Kopfsteinpflaster verlegt (Abb. 2) Im Vergleich zum ersten Bauabschnitt sind die Anbauten nachlässiger ausgeführt, auch fehlt die Feuchtigkeitssperre aus Lehm.

Ein späterer Anbau war auch der am Ende des 17. Jahrhunderts auf den Plänen (Abb. 4 und 5) vermerkte Kanonenturm in der südöstlichen Ecke der Burg, dessen Durchmesser vom Plan ausgehend etwa 9,5 m betrug. Unter Berücksichtigung der Anordnung der gesäuberten Mauern ist der meiste Teil der unteren Mauern des Turms bis heute vom Embach weggespült worden. Teilweise ist am Ufer des Flusses die Balkenunterlage, die sich unter dem Turm befand, sichtbar (Abb. 8).

Das unterschiedliche Alter des Anfangsbauwerks, des an der Nordseite durchgeführten Anbaus und des in der südöstlichen Ecke befindlichen Kanonenturms lässt sich auch durch die Tatsache beweisen, dass die Balkenunterlage in unterschiedlicher Höhe liegt. Die Unterlage des ursprünglichen Baus befindet sich auf einer Höhe von 28,97 m. Die Balkenunterlage des an der Nordseite angebauten Teils der Burg liegt aber im Vergleich dazu mehr als einen Meter

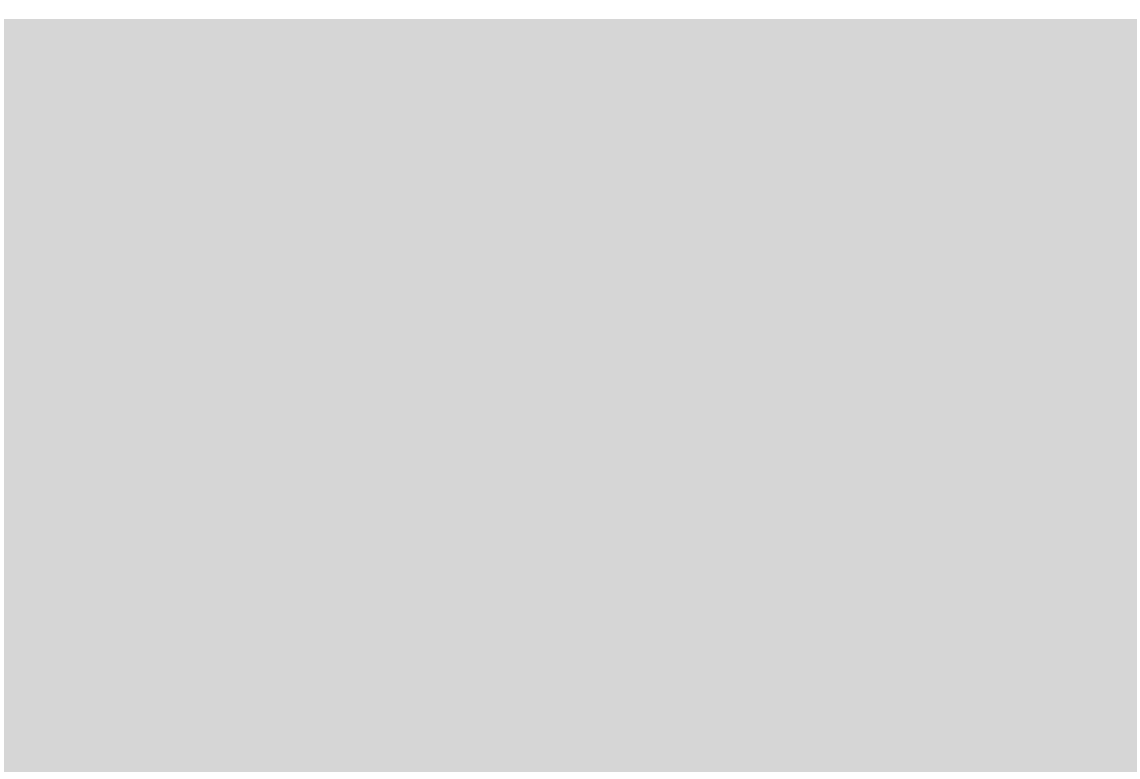

Abb. 8. Anfängliche Lage der Burg Warbeck und des Wallgrabens. Erklärung de Bezeichnungen im Text. Zeichnung von Andres Tvauri.

höher (30,03 und 30,19 m). Im Vergleich mit der Unterlage des Anbaus befindet sich die am Flussufer sichtbare Balkenunterlage in nahezu derselben Höhe (29,83-29,98 m), welche voraussichtlich zum Kanonenturm gehört hatte.

Im Hof der Burg, 4,5 m südlich von der nördlichen Mauer, führte eine mit Mörtel verbundene Steinreihe von Osten nach Westen. Im Norden dieser Reihe waren auch die Reste von wenigstens drei Steinreihen in nordsüdlicher Ausrichtung (Abb. 2) sichtbar. Offensichtlich hat sich im nördlichen Teil des Hofes ein Holzgebäude befunden (Abb. 6: 2). Diese Annahme wird auch durch die Tatsache unterstützt, dass im Bereich des vermutlichen Holzhauses im Verlauf der Ausgrabungen kein Kopfsteinpflaster gefunden wurde.

Auf Grundlage der historischen Pläne und der Feldforschung umgab die Burg ein bis zu 15 m breiter Wallgraben (Abb. 8). Im Verlauf von Ordnungsarbeiten am Ufer fand man an der Ostseite der Burg die Uferbefestigung des Wallgrabens, gemauert aus großen Feldsteinen ohne Bindungsmittel (Abb. 8: 5). Die Steine der Uferbefestigung waren in mindestens zwei Schichten angebracht. Die unterste Steinschicht stützte sich auf Planken. Im torfartigen Boden zwischen den Steinen der Uferbefestigung wurden zwei Stücke von Steinkeramikgeschirr 
gefunden. Eines davon ${ }^{64}$ stammte von einer in Köln im 16. Jahrhundert gefertigten Kanne, das andere von einer Mineralwasserflasche aus dem 18.-19. Jahrhundert. ${ }^{65}$ Bedauerlicherweise lässt sich mit Hilfe dieser Funde diese Konstruktion nicht datieren. Es ist nicht ausgeschlossen, dass es sich um die Uferbefestigung eines mittelalterlichen Wallgrabens handelte, die auch als Bootsbrücke genutzt werden konnte.

Obwohl anhand der Baureste darauf geschlossen werden kann, dass die Burg Warbeck in wenigstens zwei Etappen errichtet wurde, lässt sich auf ihrer Grundlage die genaue Zeit dieser Bauabschnitte nur sehr schwer einordnen. Aus den dendrochronologischen Forschungen ergibt sich, dass die Vorburg wenigstens als ein mit Wallgräben umgebener Bereich keine spätere Anlage ist, sondern wahrscheinlich eines der ältesten Teile der Burg. Die in den Mauern des früheren Bauabschnittes genutzten Backsteine entsprechen von ihren Maßen her $(30-31 \times 15-15,5 \times 10 \mathrm{~cm})$ den in Dorpat in der ersten Hälfte des 14. Jahrhunderts gefertigten Backsteinen. ${ }^{66}$ Bezüglich der Ziegelsteine der anfänglichen Anlage Warbecks ist ihre größere Dicke als bei gewöhnlichen Steinen auffällig. Die Dicke der auf dem estnischen Gebiet verbauten Backsteine schwankt im Zwischenraum von 8-10 cm. 9-10 cm dicke Ziegelsteine sind auch beispielsweise für das Konventhaus in Fellin sowie für die Errichtung der Burgen in Karkus (Karksi), Ringen (Rõngu) und Oldenthorn verwendet worden, die auf das 14.-15. Jahrhundert datiert worden sind. ${ }^{67}$ Auch die im Portal der im Kastell des Klosters Falkenau gegen die nordwestliche Ecke gebauten Kapelle verwendeten Backsteine waren $10 \mathrm{~cm}$ dick. ${ }^{68}$ In den nächsten Jahrhunderten blieb die typische Länge und Breite von Mauerziegeln gleich, doch in der Neuzeit verringerte sich die durchschnittliche Dicke der Backsteine und betrug im 18. Jahrhundert nur noch $6-8 \mathrm{~cm} .{ }^{69}$ Dies ist auch in der

64 TÜ 1014: 172

65 TÜ 1014: 171

66 Rivo Bernotas, „Brick-making in medieval Livonia. The Estonian example“, Estonian Journal of Archaeology, 17 (2013), 139-156.

67 Jaan Tamm, Eestis esineva ehitustellise tüpoloogia ja dateeringu väljaselgitamine. Eeltööd (Tallinn, 1974), 45. Handschrift im Archiv des Denkmalschutzamtes, Tallinn.

68 Andres Tvauri, Aruanne arheoloogilistest uuringutest Kärkna kloostri kastelli kirdenurga ja Miikaeli kabeli portaali juures 1999. aastal (Tartu, 1999), 5. Handschrift im Archiv des Denkmalschutzamtes, Tallinn.

69 Siehe: Tamm, Eestis esineva ehitustellise tüpoloogia, 35-47.
Burg Warbeck gut zu verfolgen, wo in den Mauern der Anbauten zusätzlich zu den $10 \mathrm{~cm}$ dicken Backsteinen der Anfangsanlage auch $8 \mathrm{~cm}$ dicke Ziegelsteine verwendet wurden. In den Mauern des ersten Bauabschnitts sind also für das 14.-15. Jahrhundert typische Backsteine verwendet worden, der Anbau erfolgte später, auch nach den Ausmaßen der Ziegelsteine zu urteilen. Im Verlauf der Ausgrabungen wurden die Mauern des runden Kanonenturms nicht aufgefunden, deshalb sind die Ausmaße der zu seinem Bau verwendeten Backsteine unbekannt.

Bei der Datierung der Bauabschnitte der Burg bietet das knappe und einseitige Fundmaterial keine Hilfe, das hauptsächlich aus Scherben von Keramikgeschirr besteht. Dabei wurden keine Funde aus der Schicht vor dem Bau der ursprünglichen Anlage oder aus derselben Zeit gemacht. Alle Funde wurden entweder in der bei der Errichtung des Anbaus angehäuften Füllschicht oder in den die Fußböden und Pflaster der Burg bedeckenden Schichten gesammelt. Die meisten Bruchstücke von Steingutgefäßen ${ }^{70}$ stammen von Kannen, die in Norddeutschland in Siegburg am Rhein in einem Gebiet der Keramikfertigung hergestellt wurden,${ }^{71}$ und zwar im 15. Jahrhundert oder in der ersten Hälfte des 16. Jahrhunderts. Ein Splitter stammt auch von einem Stück Geschirr, das in Raeren, in derselben Region der Töpfereimanufaktur, in der ersten Hälfte des 16. Jahrhunderts angefertigt wurde. ${ }^{72}$ Ein weiteres Bruchstück ist von einer Kanne, die in Waldenburg in Sachsen etwa 1425-1475 hergestellt wurde. ${ }^{73}$

Unter den Fundstücken sollten ein kleiner Würfel aus Knochen ${ }^{74}$ und eine Pfeife ebenfalls aus Knochen ${ }^{75}$ erwähnt werden, die in der Füllschicht des Anbaus der Burg im Nordflügel entdeckt wurden, die sowohl im Mittelalter als auch in der frühen Neuzeit angefertigt worden sein können. Auf dem Gebiet der Burg wurden Splitter von Irdenware des Pleskauer Typs aus der zweiten Hälfte des 16. Jahrhunderts gefunden, die vom anderen Ufer des

\footnotetext{
70 Festgelegt Erki Russow.

71 TÜ 1014: 34-42, 54, 60, 62-64

72 TÜ 1014: 85.

73 TÜ 1014: 61.

74 TÜ 1014: 29.

75 TÜ 1014: 138 .
} 
Peipussees stammt. ${ }^{76}$ Es wurden eine steinerne Kanonenkugel ${ }^{77}$ Fensterglassplitter mit retuschierten Rändern ${ }^{78}$ und Bruchstücke der Bleirahmen von Fenstern gefunden. ${ }^{79}$ Die letzteren belegen, dass es in der Burg verglaste Fenster gegeben hatte. Mit Sicherheit stammt nur ein Fund aus dem 17. Jahrhundert, eine schwedische 1/6-Öre Kupfermünze aus dem Jahr $1666 .{ }^{80}$ Es glückte nicht, einen Fund datiert auf die Zeit vor dem 15. Jahrhundert auf dem gesamten Areal der Burg zu machen.

Als Ergebnis der archäologischen Überwachung im Verlauf der Säuberung der Wallgräben wurden nur einige wenige Funde gemacht. Offenbar sind die Wallgräben schon früher gesäubert worden. Nur im Wallgraben zwischen Burg und Vorburg wurde ein keramischer Tintentopf aus grauem Ton mit grüner Glasur und nordwestrussischer Herkunft gefunden, ${ }^{81}$ der wahrscheinlich aus der zweiten Hälfte des 16. Jahrhunderts stammt.

Westlich von der Burg befindet sich ein etwa $60 \mathrm{~m}$ langes und breites Areal, das von einem bis zu $10 \mathrm{~m}$ breiten Wallgraben umgeben ist (Abb. 8). Dort angelegte Schächte zeigten, dass die Kulturschicht hier nur etwa $20 \mathrm{~cm}$ dick ist. Steinerne Gebäude gab es hier wahrscheinlich nicht, möglich, dass sich hier zur Zeit der Bischofsburg hölzerne Wirtschaftsgebäude befanden. Auf dem Plan des 17. Jahrhunderts (Abb. 4) sind hier der Krug und Nebengebäude vermerkt. In der nordwestlichen Ecke der Vorburg kam im Verlauf der Säuberung des Wallgrabens eine Uferbefestigung aus Balken ans Tageslicht (Abb. 8: 4). Diese bestand aus bis zu in fünf Schichten angebrachten, 10-30 cm dicken, mit der Axt behauenen Balken, die von Bewehrungen unterstützt wurden. Da die dendrochronologische Untersuchung bis jetzt noch keine Ergebnisse geliefert hat, ist das Alter der Uferbefestigung unbekannt. Die im Herbst 2001 bei der Einrichtung der Entwässerungsgräben gemachten Beobachtungen zeigten, dass auch die Außenseite des westlichen Wallgrabens der Vorburg mit einer Balkenwand befestigt war (Abb. 8: 3). Unter den

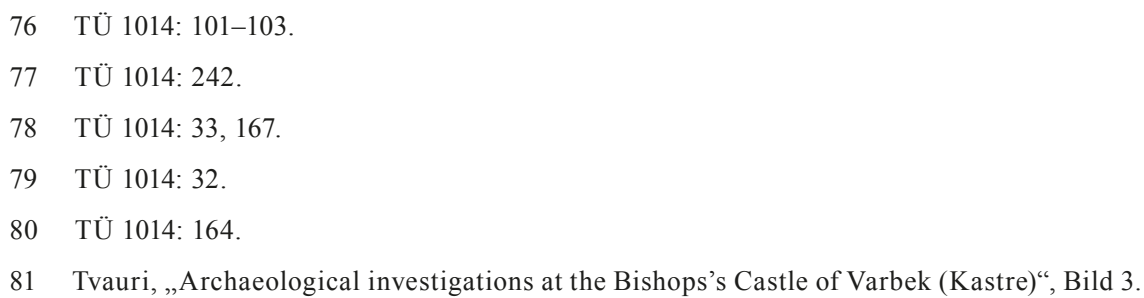

Balken kamen Reste eines für das Mittelalter typischen Dachziegels vom Typ Mönch und Nonne hervor. ${ }^{82}$

Der „Baum” im Fluss bedeutete, unbedingt einen Halt zu machen, und für die Reisenden gab es hier spätestens seit dem 17. Jahrhundert - tatsächlich wohl schon im Mittelalter - einen Krug83, dessen Gebäude auf dem Bereich der Vorburg auf dem Plan des 17 Jahrhunderts vermerkt ist (Abb. 4). Bei der Burg befand sich eine kleine Siedlung, wo es im Jahr 1601 immerhin 21 Haushalte gab, darunter waren 20 Fischer und ein Bierbrauer. Die Abgabe der Fischer für das Gut betrug zwei große Fische für die Tafel wöchentlich. ${ }^{84} 1613$ wird die Maria-Magdalena-Kapelle im Ort namens Coster erwähnt, drei Meilen entfernt von Dorpat, zu dessen Kirchengemeinde einst 200 Bauernfamilien gehört haben sollen, von denen nach Krieg und Hungersnot noch 40 übriggeblieben waren. ${ }^{85}$

Zwischen dem $300 \mathrm{~m}$ westlich von der Steinburg zur Burg führenden Weg und dem Embach befindet sich ein als archäologisches Denkmal unter staatlichen Schutz gestellter Friedhof, der um die Kapelle herumgelegen sein könnte. Zusätzlich zu menschlichen Knochen und Sargnägeln ${ }^{86}$ sind an dieser Stelle mehrere Funde ans Tageslicht gekommen, die offenbar als Grabbeigaben im Erdboden geblieben waren. Dennoch wurde hier nichts gefunden, was mit Sicherheit aus dem Mittelalter stammen würde. Als ältester Fund kann eine röhrenförmige Perle aus blauem Glas mit viereckigem Durchschnitt gelten, ${ }^{87}$ welche in Estland in Schatzfunden aus der Zeit des Livländischen Kriegs (15581582) und/oder aus dem Anfang des 17. Jahrhundert vorhanden sind, zum Beispiel im Schatz im Dorf Hirwli (Hirvli) in Harrien (Harjumaa) ${ }^{88}$ und im historisch im Kreis Fellin in Addafer (Adavere)

82 TÜ 1014: 256.

83 Das Dorpater Land 1624/27, 44: An dem Baume wirdtt Zoll genohmen.

84 Die Revision Livlands 1601, 5

85 „Protocoll der Catholischen Kirchenvisitation in Livland vom Jahre 1613“, Archiv für die Geschichte Liv-, Esth- und Curlands 1 (1842), 23-77, hier 32. Siehe auch: Lemming Rootsmäe,
Ilse Rootsmäe, Võnnu kihelkonna kohanimed ja minevik. Eesti Rahvaluule Arhiivi toimetused, Bd. 34 (Tartu: Eesti Kirjandusmuuseumi Teaduskirjastus, 2016), 217.

86 TÜ 1032: 3-6.

87 TÜ 1032: 7.

88 ERM A 462: 75 
aufgefundenen Hort. ${ }^{89}$ Auf dem Friedhof in Albenküll (Aleviküla) ist noch ein Anhänger aus dem Gehäuse einer Kaurischnecke gefunden worden, ${ }^{90}$ welche die estnische Bauernbevölkerung im Mittelalter und wenigstens bis zum Beginn des 17. Jahrhunderts getragen hatten, wie ihr Fund in dem Massengrab der Hungerund Pestzeit 1601-1603 in Reval zeigt. ${ }^{11}$ Wahrscheinlich sind eine schwedische Viertelöremünze aus dem Jahr $1634^{92}$ und eine traditionelle estnische Ringfibel, ${ }^{93}$ die vom 17. bis 19. Jahrhundert getragen wurden, Grabbeigaben.

An der Süd- und Ostseite des Friedhofs, fast bis zur Vorburg, ist die Kulturschicht einer Siedlung sichtbar, die viel Ruß, den Bruch von verbrannten Steinen und Scherben von Tongeschirr enthält. Unter den dort gesammelten Tongeschirrscherben befindet sich Keramik russischer Herkunft aus der zweiten Hälfte des 16. Jahrhunderts in der Überzahl. ${ }^{94}$ Die Irdenware des Pleskauer Typs, ${ }^{95}$ ein auf dem Gebiet Nordwestrusslands erzeugtes, mit grüner Glasur versehenes und aus grauem Ton gefertigtes Gefä $\beta^{96}$ und die Bruchstücke von aus Moskau stammenden Töpfe aus weißem Ton. ${ }^{97}$ An Geschirr westlicher Herkunft wurde hier nur ein Splitter einer in Duingen in Niedersachsen gefertigten Flasche gefunden. ${ }^{98}$ Solche Gefäße wurden auch auf dem estnischen Gebiet von der Mitte des 16. Jahrhunderts an bis zum 20. Jahrhundert genutzt. ${ }^{99}$

Wiederholt war die Burg Warbeck verbunden mit militärischen Ereignissen, wobei es sich aber nicht immer um Grenzkriege handelte. Anfang Mai 1462 schrieb der Dorpater Bischof Helmich

89 ERM A 372: 18.

90 TÜ 1168: 8.

91 Beispielsweise AI 6871: 42

92 TÜ 178.

93 TÜ 1168: 3.

94 Zur Datierung und Verbreitung derartigen Tongeschirrs auf dem estnischen Gebiet siehe Andres Tvauri, „Liivi sõja aegne keraamika Eesti linnustes ja linnades“, Linnusest ja linnast. Teadus, Bd. 14 (Tallinn, Tartu: Teaduste Akadeemia Kirjastus, 2004), 395-419.

95 AI 5460; TÜ 98: 1.

96 TÜ 1032: 18.

97 AI 5460; TÜ 1032: 36.

98 TÜ 1032: 13.

99 Erki Russow, Importkeraamika Lääne-Eesti linnades 13.-17. sajandil (Tallinn: Tallinna Ülikooli Ajaloo Instituut, 2006), 76. von Mallinkrodt (1459-1468) an den Lübecker Rat, wie der Dorpater Bürger Hermann Bernstorp mit seinen Genossen einen Angriff auf die Burg Warbeck durchgeführt hatte. Er „plünderte, beraubte und bestahl diese vorher erwähnte Burg und nahm von dort auch Kanonen, Schießpulver, Harnische und viele andere Waren, Geschmeide, Kleinode und allerhand Lebensmittel mit“. Bernstorp versenkte noch drei bei der Burg gelegene Boote (snychen) und segelte dann zusammen mit dem Diebesgut nach Russland. ${ }^{100}$ Es handelte sich um einen privaten Streit, der aus unbekannten Gründen ausgebrochen war und in den sich der Dorpater Rat und der Bischof eingemischt hatten. Dies war ein Streitfall über mehrere Jahrzehnte und dabei bei weitem nicht der einzige im damaligen Bistum Dorpat. Im Jahr 1454 hatte der weitverbreitete Streit zwischen den Adelsgeschlechtern der Stamers und der Vrorips und der Stadt Dorpat begonnen, in den nicht nur der Dorpater Bischof und das Domkapitel sowie andere livländische Städte hineingezogen wurden, sondern sogar der König von Dänemark. Damit nahm der Streit zeitweilig den Charakter eines Krieges an. ${ }^{101}$ Über Hermann Bernstorp wissen wir, dass er 1453 der Gesandte der livländischen Städte in Nowgorod war. ${ }^{102}$ Am Ende des Jahrzehnts, 1460, erbat der Städtetag in Walk aber die Hilfe des livländischen Ordensmeisters, um Bernstorps - der Dorpat dermaßen übereilt verlassen hatte oder geflüchtet war, dass sogar dessen Siegel zurückgeblieben war und sich in der Hand des Dorpater Rats befand - und Otto van Dalens Streitfall zu lösen. ${ }^{103}$ Es handelte sich um eine 2000 Mark große Geldsumme und der Dorpater Rat gab später wenigstens teilweise $z u$, dass Bernstorp berechtigt war eine Entschädigung zu erhalten. ${ }^{104}$ Zum Zeitpunkt des Wagnisses von Warbeck hatte Bernstorp van Dalen gefangen genommen und nach Russland

100 Liv-, Est- und Kurländisches Urkundenbuch, Bd. 12, Nr. 143; vgl. Nr. 186; Urkundenbuch der Familie von Mallinckrodt, Bd. 1, hrsg. von Gustav von Mallinckrodt (Bonn: Georgi, 1911), Nr. 246, 127.

101 Philipp Schwartz, „Die Fehde Dorpats mit den Stamern und Genossen“, Sitzungsberichte der Gesellschaft für Geschichte und Alterthumskunde der Ostseeprovinzen Russlands aus dem Jahre $1902(1903), 158-169$.

102 Hanserecesse 2. Abtheilung von 1431-1476, Bd. 4, hrsg. von Goswin von der Ropp (Leipzig: Duncker \& Humblot, 1883), Nr. 181. Der Kaufmann Hermann Bernstorp wurde auch 1437 erwähnt: Hansisches Urkundenbuch, Bd. 7/1, hrsg. von Hans-Gerd von Rundstedt (Weimar: Böhlaus Nachfolger, 1939), Nr. 292.

103 Hanserecesse 2. Abtheilung von 1431-1476, Bd. 4, Nr. 757.

104 Liv-, Est- und Kurländisches Urkundenbuch, Bd. 12, Nr. 101. 
verschleppt. ${ }^{105}$ Die Geschichte selbst muss sich nach 1453 ereignet haben und bevor der Dorpater Bischof Bartholomäus Savijerwe im Jahr 1459 von seinem Amt zurücktrat. 1461 war Hermann Bernstorp bereits in Lübeck und forderte dort sein Recht. Er suchte Hilfe beim Grafen von Oldenburg und beim Bischof von Münster. ${ }^{106}$ Der Streitfall, bei dem der Bischof von Dorpat nicht nachgeben wollte und der Kläger ungeachtet der ihm versprochenen Sicherheiten und dahingehenden Aufforderungen offensichtlich nicht persönlich nach Livland reiste, war noch in den Jahren 1477-1478 ungelöst, als der sich in Norddeutschland aufhaltende Bernstorp wiederholt gegen die Städte Riga, Dorpat und Reval klagte. ${ }^{107}$

In der Zeit des nach der Unterwerfung Nowgorods durch den Großfürsten von Moskau ausgebrochenen Russisch-Livländischen Kriegs im Februar 1480 rückten die Streitkräfte Pleskaus über den Peipussee und den Embach in das Bistum Dorpat vor. Diese Truppe lagerte drei Tage und Nächte vor der Burg Warbeck, bis die Besatzung der Burg die Aussichtslosigkeit ihrer Lage erkennend sich ergab und in Gefangenschaft ging. Unter den Gefangenen waren 52 Frauen und Kinder. Die Russen machten in Warbeck eine große Kriegsbeute, darunter Kanonen und Schießpulver und brannten die Burg nieder, bevor sie nach Dorpat weiterzogen. ${ }^{108}$

Im Livländischen Krieg war Warbeck eine der ersten Burgen, die den Russen in die Hände fiel. Am 5. oder 6. Juli 1558 überraschten ein 30 Mann starker russischer Stoßtrupp („Kosaken“) und einige Hakenbüchsenschützen nachts auf Booten kommend die Burg. Sie zündeten die Tore der Burg an, bevor die Besatzung der Burg mit der Verteidigung beginnen konnte. Da nun die Burgleute Widerstand für zwecklos hielten, übergaben sie Warbeck den Russen und ließen sich

105 Liv-, Est-und Kurländisches Urkundenbuch, Bd. 12, Nr. 143.

106 Ibidem, Nr. 101, 108, 142.

107 Ibidem, Nr. 101, 186, 214, vgl. Nr. 287, 319; Hanserecesse, 2. Abtheilung von 14311476, Bd. 5, hrsg. von Goswin von der Ropp (Leipzig: Duncker \& Humblot, 1888), Nr. 383 Hanserecesse 3. Abtheilung von 1477-1530, Bd. 1, hrsg. von Dietrich Schäfer (Leipzig: Duncker Duncker \& Humblot, 1899), Nr. 1140; Urkundenbuch der Familie von Mallinckrodt $\mathrm{Bd}$. 1 , Nr. 238, 123-124; Nr. 248, 127; Liv-, Est- und Kurländisches Urkundenbuch. Abteilung 1, Bd. 13, hrsg von Madlena Mahling, Klaus Neitmann, Matthias Thumser (Köln, Weimar, Wien: Böhlau, 2017), Nr. G050 (im Erscheinen).

108 Pskovskie letopisi, Bd. 1, 77; Pskovskie letopisi, Bd. 2, 59, 220, 236; Marina B. Bessudnova, Rossija i Livonija v konce XV veka. Istoki konflikta (Moskau: Kvadriga, 2015), 143. mit dem Burggrafen an der Spitze gefangen nehmen. ${ }^{109}$ Das schnelle Erlahmen des Widerstands des Bistums Dorpat rief in Livland eine Reihe von Klagen über den Verrat der Stadt und der Leute des Bischofs hervor. Über Warbeck schrieb der im Dienst des Deutschen Ordens befindliche Chroniker Johann Renner (gest. 1583), dass irgendein Dorpater Bürger die in der Burg sich aufhaltenden Landsknechte betrunken gemacht hatte und dann die Russen herbeirief, welche die Deutschen in ihren Betten überraschten. Der Gefangennahme entgingen nur jene Mitglieder der Burgbesatzung, denen es gelang, von der Mauer herunterzuspringen und lebendig und gesund $\mathrm{zu}$ fliehen. ${ }^{110}$

Obwohl die Burg vor allem eine militärische Anlage gewesen war, wurden in der Burg Warbeck keine Waffen oder Waffenteile gefunden. Zur Munition kann nur eine kleine, steinerne Kanonenkugel gezählt werden, die in der durch den Abriss oder den Zerfall der Burg entstandenen Trümmerschicht gefunden wurde. ${ }^{111}$ Belege für Gewalt wurden dennoch gefunden. Nämlich kam im Innern des sich an der Westseite der Burg befindlichen viereckigen, vermutlichen Turms eine Ansammlung von Menschenknochen ans Tageslicht, es handelt sich um die Überreste von wenigstens zwei erwachsenen Männern. ${ }^{112}$ An beiden aufgefunden Schädeln fanden sich Hiebspuren, die für sie wahrscheinlich tödlich waren. Die Knochen waren bereits von ihrem Fundort irgendwo woanders hin umgebettet worden, denn es war nur ein Teil des Knochengerüsts vorhanden und unter den Knochen befanden sich auch solche von Tieren. Ebenso fand sich an den Schädeln roter Sand, den es am Fundort nicht gab. Unter den Knochen waren zwei Splitter von Porzellangeschirr, ${ }^{113}$ die aus

109 Karl von Busse, „Die Einnahme der Stadt Dorpat im Jahre 1558 und die damit verbundenen Ereignisse“, Mittheilungen aus dem Gebiete der Geschichte Liv-, Ehst- und Kurlands, 1 (1840), 450-522, hier 469-471, vgl. 511-512; Herzog Albrecht von Preußen und Livland (1557-1560). Regesten aus dem Herzoglichen Briefarchiv und den Ostpreußischen Folianten, hrsg. von Stefan (Köln, Weimar, Wien: Böhlau, 2006), Nr. 2466, 345, vgl. 347.

110 Johann Renner, Livländische Historien 1556-1561, hrsg. von Peter Karstedt. Veröffentlichungen der Stadtbibliothek Lübeck. Neue Reihe, Bd. 2 (Lübeck: Schmidt-Römhild, 1953), 32.

111 TÜ 1014: 242

112 Die Knochen werden in einer für die Burg errichteten Gebäude aufbewahrt, im Erdgeschoss unter einem Glas unter dem Fußboden, das gedacht ist zur Ausstellung der Mauern der Burg zusammen mit einigen bei den archäologischen Ausgrabungen entdeckten Funden.

113 TÜ 1014: 210, 211 
der zweiten Hälfte des 18. Jahrhunderts stammen oder aus dem 19. Jahrhundert. Die Knochen sind damit wahrscheinlich im Verlauf des Baus des Kruggebäudes gefunden und umgebettet worden. Ob die Männer während irgendeines in den schriftlichen Quellen bekannten Konflikts starben oder die Knochen Zeugen eines Verbrechens sind, dies lässt sich auf Basis der vorhandenen Angaben nicht sagen.

Warbeck blieb in der Hand der Russen bis an die Übergabe an den König Polens 1582 entsprechend den Bedingungen des Vertrags (Waffenstillstands) von Jam Zapolski. Im selben Jahr wurde im polnischen Revisionsakt geschrieben, dass das momentan zerfallene Warbeck eine Burg des Dorpater Bischofs gewesen war, in der die fortgesetzte Aufgabe gesehen wurde, ein „Dorpater Blockhaus gegen Moskau“ zu sein. ${ }^{114}$ Doch ob wegen der Zerstörungen, aus militärischen oder wirtschaftlichen Erwägungen, die Polen führten das Gut Warbeck an einen neuen Ort am anderen Ufer des Flusses über, wo es sich spätestens seit dem Jahr 1591 befand, ,,als kürzlich erbaut“ durch den Dorpater königlichen Ökonomen (Verwalter der königlichen Güter) Stanisław Łoknicki. ${ }^{115}$ Unter schwedischer Herrschaft in der Mitte des 17. Jahrhunderts war die Burg noch in ausreichend gutem Zustand, dass es in der Zeit des Russisch-Schwedischen Kriegs im Sommer 1656 den Schweden noch glückte, sie in einem verteidigungsfähigen Zustand zu bringen und dort eine vierzigköpfige Garnison unterzubringen. Doch als aber die russischen Streitkräfte über Neuhausen und Kirrumpäh nach Dorpat gelangt waren, übernahmen die Russen am 12. oder 13 August Warbeck, wo die Soldaten schon auseinandergelaufen waren, so dass sich auch die Offiziere ergeben mussten. ${ }^{116}$ Dennoch zeigen die ziemlich hohen Verluste unter den Angreifern, dass die Burg damals noch zu verteidigen war. Auch gab es hier genug Platz für die russische Besatzung aus 200 Fußsoldaten. ${ }^{117}$ In der Hand der Russen blieb Warbeck bis zum Frieden von Kardis (Kärde) im Jahr 1661. Auch in der zweiten Hälfte des 17. Jahrhunderts hatte die Burg noch nicht ihre militärische

114 Polnische Akten I: 1582-1591, 112

115 Polnische Akten I: 1582-1591, 306. Vgl. Friedrich Konrad Gadebusch, Livländische Jahrbücher, Bd. 2/2 (Riga: Hartknoch, 1781), 449.

116 Friedrich Bienemann, „Briefe und Aktenstücke zur Geschichte der Verteidigung und Kapitulation Dorpats 1656“, Mittheilungen aus dem Gebiete der Geschichte Liv-, Est- und Kurlands, 16 (1896), 515-606, hier 546-549; Erik Tender, Tartu vallutamine venelaste poolt 1656. aastal. Äratrükk Tartu linna väljaandest Tartu VI (Tartu: Tartu linn, 1939), 7, 12.

117 Aleksej N. Lobin, Nikolai V. Smirnov, „Bor’ba za Jur'ev-Livonskij v gody Russkosvedskoj vojny (1656-1658)“, Vojna i oružie. Novye issledovanija i materialy, Bd. 1, hrsg. von Sergej V. Efimov (St. Peterburg: VIMAIViVS, 2011), 534-549, hier 539.
Bedeutung verloren, ebenso planten die Schweden noch am Ende des Jahrhunderts, diese weiter zu befestigen und gründlich umzubauen 1704 aber lag die Burg tatsächlich immer noch in Ruinen. ${ }^{118}$ Nach dem Nordischen Krieg, bereits an einer Binnengrenze des Russischen Reichs zwischen zwei Provinzen, verlor die Burg Warbeck auch ihre potentielle militärische Bedeutung. In der zweiten Hälfte des 18. Jahrhunderts war aus der Burg bereits ein "Steinhaufen" geworden, ${ }^{119}$ auf dem die Burgschenke errichtet wurde. ${ }^{120}$

Anti Selart, Andres Tvauri, Alar Läänelaid: Kastre Castle Keywords: Medieval Livonia; Medieval Castles; DendroChronology; Medieval archaeology; Tartu; Pskov; Lake Peipus

\section{SUMMARY}

Kastre (sometimes called Uue-Kastre) Castle on the north shore of the Emajõgi River has been almost totally destroyed. At one time it belonged to the Tartu bishops, and a trade route connecting the Baltic Sea countries and Russia through Tartu and Pskov ran past the castle. In the Middle Ages, this also marked the actual boundary of the Tartu bishopric, since only unsettled wetlands covered the area between the castle and the lake. The Kastre Castle is mentioned in the written records for the first time in 1392 as a customs checkpoint, in connection with a treaty between the Hanseatic towns and Novgorod. There was a barrier near the castle that was stretched over the river with a rope or chain, which stopped the boats and ships from sailing through without stopping. When the Pskovians launched a military expedition on their lod'ya boats against the Tartu bishopric in 1342, there is no mention of the Kastre Castle. The place name is probably based on the Old Russian word koster' (костерг), which meant

118 Umbaupläne wurden auch in der ersten Hälfte der fünfziger Jahre des 17. Jahrhunderts diskutiert. Siehe: Löwis of Menar, Burgenlexikon, 120; Ulla Ehrensvård, „Topographica Estoniae. Seltsi Rootsis Aastaraamat, 12/1991-1999 (2001), 5-289, hier 54, 113, 230-234.

119 Hupel, Topographische Nachrichten, Bd. 1, 263

120 Rootsmäe, Rootsmäe, Võnnu kihelkonna kohanimed, 202-205. 
stronghold and has been used as a loan word in the eastern Finnic languages. The German name of Kastre is Warbek, and the current explanation is that this meant "river defence" (Middle German were des bekes). However, were has also meant fish barrier, i.e. a fishing structure built across the flow of the river.

In 1993, the owner of the castle property had the moats around surrounding the castle and outer bailey dredged and widened, which changed their location and appearance notably. The first archaeological studies at the castle were conducted to verify the damage caused by this unauthorised excavation work. In 1994, the profile of the ground exposed by excavator rooting around in the moats was documented. In 2001, the first archaeological excavations took place at the site of the Kastre Castle. There were plans to build a new structure between the walls of the tavern that had been built on the site of the castle in the late $18^{\text {th }}$ and $19^{\text {th }}$ century, and the necessary trenches were dug in the course of the archaeological rescue excavations. Supervision of the construction work, as well as excavation work related the cleanup of the moats and surrounding property, continued for the next few years. Depending on the location, the excavations reached the cobblestone paving that was located $40-120 \mathrm{~cm}$ below the prior ground level in the courtyard and interiors of the castle.

In 2001, wood samples were taken from the logs that were revealed on the western slope of the western moat of the Kastre outer bailey, and had been used to fortify the incline. The dendrochronological study shows that the logs were fell after the 1376 growth period (summer). Therefore, the moat of the Kastre outer bailey was probably fortified in 1377. The direct motivation for building the castle may have been the border war between Pskov and the Tartu bishopric that lasted from 1367 to 1371 . The main battlefield of the war was Lake Peipsi, and a dispute about the fishing rights in Lake Lämmijärv has been given as the main explanation for the war.

Kastre was a very important medieval fishery centre for the lower Emajõgi River and Lake Peipsi. Here the import of fish was taxed. In the vicinity, one could find the fishing grounds of the Tartu bishop, the Cathedral Chapter, the town of Tartu, monasteries and private manors, as well as of the Teutonic Order. The water and winter roads that ran through Kastre from Tartu toward Russia or Narva comprised an important traffic zone, which the castle controlled. Kastre was the centre of the relevant Tartu bishopric's administrative division. The bishops are said to have visited the border castle personally on many occasions, so suitable rooms must have existed at the castle. An idea of the castle is provided by plans from $17^{\text {th }}$ century.

The castle was built in at least two stages. Its foundations were built on log floats. First an unusual rectangular building of fieldstones and bricks was built, the longest wall of which was 17,5 metres and the shortest 12 metres; the walls were 2,5 to 2,8 metres thick. The walls on the north and northwest side of the castle were built later against the originally planned walls; whereas the upper parts of the original northern and eastern walls were demolished. A subsequent addition was the cannon tower on the southeast corner of the castle, which is indicted on plans from the late $17^{\text {th }}$ century, and the diameter of which, based on these plans, would have been about 9,5 metres. Considering the location of the walls that have been revealed, most of the tower's foundation walls have been washed away by the Emajõgi River. Apparently a wooden building was located in the northern part of the castle's courtyard. The castle was surrounding by a moat that was up to 15 metres wide. It is not possible to determine the exact time of the different stages of construction. From the dendrochronological studies we can conclude that the outer bailey, or at least the area surrounded by moats, is not a later construction but most probably one of the oldest parts of the castle. Bricks typical of the $14^{\text {th }}$ and $15^{\text {th }}$ centuries have been used in the walls of the first construction stage; the addition, based on the dimensions of the bricks, is a later construction. There have been no finds on the entire property that date back to the period before the $15^{\text {th }}$ century.

On the west side of the castle, there is an area that is about 60 metres long and wide, and surrounded by a 10-metre-wide moat. The cultural layer here is only a ten or so centimetres thick. There were probably no stone buildings here; but it's possible that wooden outbuildings were already located here when it was a bishopric castle. A tavern and outbuildings are indicated on the $17^{\text {th }}$ century plans. In the course of cleaning the moats, wooden shore fortifications came to light in the northeast corner of the outer bailey. There was a small settlement near the castle, which, in 1601, included 21 households - 20 of them fishers and one brewer. A Mary Magdalene chapel is mentioned in 1613 here. A cemetery is located on the western side of the castle, which could have surrounded a chapel. 
The Kastre Castle has been repeatedly associated with military events, such as border wars and internal conflicts. In the Livonian War, Kastre was one of the first castles that fell into the hands of the Russians in 1558. Based on the Truce of Yam-Zapolsky, the castle was transferred to Poland in 1582. During the Russo-Swedish War in 1656, the Swedes were able make repairs the castle and make it defensible, and they stationed a garrison there. However, it still fell into Russian hands until the Treaty of Kärde was signed in 1661. In the late $17^{\text {th }}$ century, the Swedes planned to completely rebuild the castle. But as of 1704, the castle was still in ruins. After the Great Northern War, being inside the borders of the Russian Empire, the Kastre Castle lost its potential military importance. By the second half of the $18^{\text {th }}$ century, the castle had turned into "a pile of stones", from which a tavern was built.

\section{CV}

Dr. Anti Selart (b. 1973) is Professor of Medieval History at the University of Tartu. He has researched various topics related to the medieval and $16^{\text {th }}$ century history of Livonia, including the relations between Livonia and Russia.

Dr. Andres Tvauri (b. 1970) is a Senior Research Fellow in Archaeology at the University of Tartu. His researched has focused on the Iron Age in Estonia, but he has also dealt extensively with medieval and modern era archaeology.

Dr. Alar Läänelaid (b. 1951) is Associate Professor in Landscape Ecology at the University of Tartu. He has researched Estonian flora and developed a dating technique for wooden objects by using dendrochronological methods. 